\title{
Active Crossfire Between Cyanobacteria and Cyanophages in Phototrophic Mat Communities Within Hot Springs
}

\author{
Sergio Guajardo-Leiva ${ }^{1}$, Carlos Pedrós-Alió ${ }^{2}$, Oscar Salgado ${ }^{1}$, Fabián Pinto $^{1}$ and \\ Beatriz Díez ${ }^{1,3 *}$ \\ ${ }^{1}$ Department of Molecular Genetics and Microbiology, Pontificia Universidad Católica de Chile, Santiago, Chile, ${ }^{2}$ Programa \\ de Biología de Sistemas, Centro Nacional de Biotecnología - Consejo Superior de Investigaciones Científicas, Madrid, \\ Spain, ${ }^{3}$ Center for Climate and Resilience Research, Santiago, Chile
}

OPEN ACCESS

Edited by:

Rui Zhang,

Xiamen University, China

Reviewed by:

Purificacion Lopez-Garcia Centre National de la Recherche Scientifique (CNRS), France

Yongle $\mathrm{Xu}$,

Shandong University, China

${ }^{*}$ Correspondence: Beatriz Díez bdiez@bio.puc.cl

Specialty section: This article was submitted to

Aquatic Microbiology,

a section of the journal

Frontiers in Microbiology

Received: 10 April 2018

Accepted: 13 August 2018 Published: 03 September 2018

Citation:

Guajardo-Leiva S, Pedrós-Alió C, Salgado O, Pinto F and Díez B (2018)

Active Crossfire Between Cyanobacteria and Cyanophages in Phototrophic Mat Communities Within Hot Springs.

Front. Microbiol. 9:2039. doi: 10.3389/fmicb.2018.02039
Cyanophages are viruses with a wide distribution in aquatic ecosystems, that specifically infect Cyanobacteria. These viruses can be readily isolated from marine and fresh waters environments; however, their presence in cosmopolitan thermophilic phototrophic mats remains largely unknown. This study investigates the morphological diversity (TEM), taxonomic composition (metagenomics), and active infectivity (metatranscriptomics) of viral communities over a thermal gradient in hot spring phototrophic mats from Northern Patagonia (Chile). The mats were dominated (up to 53\%) by cosmopolitan thermophilic filamentous true-branching cyanobacteria from the genus Mastigocladus, the associated viral community was predominantly composed of Caudovirales (70\%), with most of the active infections driven by cyanophages (up to 90\% of Caudovirales transcripts). Metagenomic assembly lead to the first full genome description of a T7like Thermophilic Cyanophage recovered from a hot spring (Porcelana Hot Spring, Chile), with a temperature of $58^{\circ} \mathrm{C}$ (TC-CHP58). This could potentially represent a world-wide thermophilic lineage of podoviruses that infect cyanobacteria. In the hot spring, TC-CHP58 was active over a temperature gradient from 48 to $66^{\circ} \mathrm{C}$, showing a high population variability represented by 1979 single nucleotide variants (SNVs). TC-CHP58 was associated to the Mastigocladus spp. by CRISPR spacers. Marked differences in metagenomic CRISPR loci number and spacers diversity, as well as SNVs, in the TC-CHP58 proto-spacers at different temperatures, reinforce the theory of coevolution between natural virus populations and cyanobacterial hosts. Considering the importance of cyanobacteria in hot spring biogeochemical cycles, the description of this new cyanopodovirus lineage may have global implications for the functioning of these extreme ecosystems.

Keywords: hot-springs, cyanophages, phototrophic microbial mat, CRISPR, thermophilic cyanobacteria

\section{INTRODUCTION}

Hot springs host microbial communities dominated by a limited variety of microorganisms that form well-defined mats (Uldahl and Peng, 2013; Inskeep et al., 2013). Frequently, the uppermost layer of the mat is composed of photoautotrophs; such as oxygenic phototrophic cyanobacteria, including the unicellular cyanobacterium Synechococcus spp. (Steunou et al., 2006, 2008; 
Bhaya et al., 2007; Klatt et al., 2011), the filamentous nonheterocystous Oscillatoria spp., the filamentous heterocystous Mastigocladus spp. (Stewart, 1970; Miller et al., 2006; Mackenzie et al., 2013; Alcamán et al., 2015), as well as filamentous anoxygenic phototrophs (FAPs), such as Roseiflexus sp. and Chloroflexus sp. (Van der Meer et al., 2010; Klatt et al., 2011; Liu et al., 2011). These primary producers interact with heterotrophic prokaryotes through element and energy cycling (Klatt et al., 2013). Heterocystous cyanobacteria are a key component in hot springs, since these systems are commonly N-limited due to the rapid assimilation and turnover of inorganic nitrogen forms (Alcamán et al., 2015; Lin et al., 2015). Thus, $\mathrm{N}_{2}$ fixation by cyanobacteria is identified to be a key biological process in neutral hot spring microbial mats (Alcamán et al., 2015).

These simplified but highly cooperative communities have been historically used as models for understanding the composition, structure, and function of microbial consortia (Klatt et al., 2011; Inskeep et al., 2013). The role of a variety of abiotic factors, such as $\mathrm{pH}$, sulfide concentration, and temperature, in determining microbial assemblages and life cycles in these ecosystems have been investigated (Cole et al., 2013; Inskeep et al., 2013). However, there is a lack of investigation into biotic factors, such as viruses, on thermophilic photoautotrophic mats, with existing studies only reporting short or partial viral sequences (Heidelberg et al., 2009; Davison et al., 2016). Currently, viral communities from thermal mats have been characterized through indirect approaches, indicating the hypothetical presence of viruses (Heidelberg et al., 2009; Davison et al., 2016). Heidelberg et al. (2009) used CRISPR spacer sequences extracted from the genomes of two thermophilic Synechococcus isolates, from a phototrophic mat in Octopus Spring. Subsequently, they searched for viral contigs from previously published water metaviromes from the Octopus and Bear Paw Springs in Yellowstone National Park (United States) (Schoenfeld et al., 2008). Furthermore, Davison et al. used CRISPR spacers and nucleotide motive frequencies to link viral contigs to known hosts using a metavirome obtained by Multiple Displacement Amplification (MDA) of VLPs from a mat in Octopus Spring (Davison et al., 2016), as well as reference genomes from dominant species (Synechococcus sp., Roseiflexus sp., and Chloroflexus sp.) previously described in the same microbial mat. A key finding from these studies was the link between viruses and their hosts, indicating their co-evolution and an effective "arms race" within hot spring phototrophic mats.

Unlike thermophilic mat studies, most viral investigation carried out in hot springs occur within the source waters (Rachel et al., 2002; Yu et al., 2006; Schoenfeld et al., 2008; Bolduc et al., 2012, 2015; Zablocki et al., 2017). In these waters, virus abundances range between $10^{4}$ and $10^{9}$ virus like particles (VLPs) $\mathrm{mL}^{-1}$ (Breitbart et al., 2004; Schoenfeld et al., 2008; Redder et al., 2009). They play an important role in both the structuring of host populations and as drivers of organic and inorganic nutrient recycling (Breitbart et al., 2004). The majority of the viruses were dsDNA, with new and complex viral morphotypes, distinct to the typical head and tail morphologies (Rachel et al., 2002; Prangishvili and Garrett, 2004; Schoenfeld et al., 2008; Redder et al., 2009; Pawlowski et al., 2014). Furthermore, the few metaviromes obtained in thermal waters indicate that natural thermophilic virus communities differ from those obtained in culture, given that there was only a $20-50 \%$ similarity between the sequences obtained and those in the databases (Pride and Schoenfeld, 2008; Schoenfeld et al., 2008; Diemer and Stedman, 2012; Bolduc et al., 2015). Thus far, the genomes that have been isolated and sequenced from thermophilic viruses (57 genomes, of which 37 infected archaea and 20 infected Bacteria) generally yielded few significant matches to sequences in public databases (Uldahl and Peng, 2013). More recently, a water metaviromic study from Brandvlei hot spring (BHS), South Africa (Zablocki et al., 2017) reported the presence of two partial genomes (10 $\mathrm{kb}$ and $27 \mathrm{~kb}$ ), the first related to Podoviridae and the second to lambda-like Siphoviridae families. Both Caudovirales genomes did not have a confirmed host, but the presence of green microbial mat-patches around the contours of the hot spring, implied that filamentous Cyanobacteria and unclassified Gemmata species were the potential hosts, respectively. The last, based on the proximity of some viral predicted proteins with bacteria from well characterized microbial mats present in a nearby hot spring (Tekere et al., 2011; Jonker et al., 2013).

Given the lack of knowledge of viral communities within hot spring phototrophic microbial mats, the present study used the mats of Porcelana hot spring (Northern Patagonia, Chile), as a pH neutral model, to better understand the associated thermophilic viral communities within these mats. This pristine spring is covered by microbial mats that grow along a thermal gradient between 70 and $46^{\circ} \mathrm{C}$, dominated by bacterial phototrophs, such as filamentous cyanobacteria from the genus Mastigocladus (Mackenzie et al., 2013; Alcamán et al., 2015). This is the dominant and most active cyanobacterial genus in the Porcelana mat environment, carrying out important biological processes such as carbon- and $\mathrm{N}_{2}$-fixation (Alcamán et al., 2015, 2017). Thus, this study proposes that the mats in Porcelana hot spring are dominated by viral communities of the Order Caudovirales, which is able to infect Cyanobacteria, preferably Mastigocladus spp.

The viral diversity in Porcelana was determined through the detection of viral signals in microbial mat omics data, and by TEM along the thermal gradient. The results demonstrate that the viral community was dominated by Caudovirales, which actively infect Cyanobacteria. Furthermore, the first complete genome description of a thermophilic cyanobacterial T7-like podovirus, Thermophilic Cyanophage Chile Porcelana $58^{\circ} \mathrm{C}$ (from now on TC-CHP58) is realized. The host is the dominant phototroph Mastigocladus spp, based on CRISPR spacers. Finally, the presence of different populations of this new podovirus are identified through single nucleotide variants (SNVs) analyses, and the co-evolution of Mastigocladus spp. and particular populations of TC-CHP58 at different temperatures is described through association of specific SNVs to different CRISPR spacers. 


\section{MATERIALS AND METHODS}

\section{Sampling Site}

Porcelana hot spring is located in Chilean Patagonia $\left(42^{\circ} 27^{\prime}\right.$ $29.1^{\prime \prime} \mathrm{S}-72^{\circ} 27^{\prime} 39.3^{\prime \prime} \mathrm{W}$ ). It has a neutral $\mathrm{pH}$ range between 7.1 and 6.8 and temperatures ranging from 70 to $46^{\circ} \mathrm{C}$, when sampled on March 2013. Phototrophic microbial mats growing at 66, 58, and $48^{\circ} \mathrm{C}$ were sampled using a cork borer of $7 \mathrm{~mm}$ diameter. Cores of $1 \mathrm{~cm}$ thick were collected in triplicate at noon (12:00 $\mathrm{PM})$, transported in liquid nitrogen and kept at $-80^{\circ} \mathrm{C}$ until DNA and RNA extraction.

\section{Transmission Electron Microscopy}

Five liters of interstitial fluid was squeezed using $150 \mu \mathrm{m}$ sterilized polyester net SEFAR PET 1000 (Sefar, Heiden, Switzerland) and filtered through $0.8 \mu \mathrm{m}$ pore-size polycarbonate filters (Isopore ATTP, $47 \mathrm{~mm}$ diameter, Millipore, Millford, MA, United States) and $0.2 \mu \mathrm{m}$ pore-size (Isopore GTTP, $47 \mathrm{~mm}$ diameter, Millipore) using a Swinex filter holder (Millipore). Particles in the $0.2 \mu \mathrm{m}$ filtrate were concentrated to a final volume of approximately $35 \mathrm{ml}$ using a tangential-flow filtration cartridge (Vivaflow 200, $30 \mathrm{kDa}$ pore size, Vivascience, Lincoln, United Kingdom). Viral concentrates (15 $\mu \mathrm{L})$ were spotted onto Carbon Type-B, 200 mesh, Copper microscopy grids (Ted Pella, Redding, California, United States), stained with 1\% uranyl acetate and imaged on an FEI Tecnai T12 electron microscope at $80 \mathrm{kV}$ (FEI Corporate, Hillsboro, OR, United States) with attached Megaview G2 CCD camera (Olympus SIS, Münster, Germany). Imaging analysis was done at the Advanced Microscopy Unit, School of Biological Sciences at Pontificia Universidad Católica de Chile (Santiago, Chile).

\section{Nucleic Acid Extractions and High Throughput Sequencing}

Nucleic acids (DNA and RNA) were extracted as previously described (Alcamán et al., 2015). For RNA, Trizol (Invitrogen, Carlsbad, CA, United States) was added to the mat sample, and homogenized by bead beating, two pulses of $20 \mathrm{~s}$. Quality and quantity of the extracted nucleic acids were checked and kept at $-80^{\circ} \mathrm{C}$.

Samples were sequenced by Illumina Hi-seq technology (Research and Testing Laboratory, Texas, United States). Briefly, for metagenomes, DNA was fragmented using NEBNext dsFragmentase (New England Biolabs, Ipswich, MA, United States), followed by DNA clean up using column purification, and a NEBUltra DNA Library Prep Kit for Illumina (New England Biolabs, Ipswich, MA, United States) was used for library construction.

For metatranscriptomes, DNase treated total RNA was cleaned up of rRNA by a Ribo-Zero rRNA Removal Kit Bacteria (Illumina, San Diego, CA, United States), followed by purification using an Agencourt RNAClean XP Kit (Beckman Coulter, Indianapolis, IN, United States), and a NEXTflex ${ }^{\mathrm{TM}}$ Illumina Small RNA Sequencing Kit v3 (Bio Scientific, Austin, TX, United States) was used for library construction.
For quality filtering, the following filters were applied using Cutadapt (Martin, 2011), leaving only mappable sequences longer than $30 \mathrm{bp}$ (-m 30), with a $3^{\prime}$ end trimming for bases with a quality below 28 (-q 28), a hard clipping of the first five leftmost bases $(-\mathrm{u} 5)$, and finally a perfect match of at least $10 \mathrm{bp}(-\mathrm{O}$ 10) against the standard Illumina adaptor. Finally, the removal of sequences representing simple repetitions that are usually due to sequencing errors was applied using PRINSEQ (Schmieder and Edwards, 2011) DUST threshold 7 (-lc_method dust, lc_threshold 7). Details of the number of sequences obtained are shown in Supplementary Table S1.

\section{Identification of rRNA-Like Sequences and Viral Mining From Metagenomes and Metatranscriptomes}

Metagenomic Illumina TAGs (miTAGs) (Logares et al., 2014) that are small subunit (SSU) $16 \mathrm{~S}$ and $18 \mathrm{~S}$ rRNA gene sequences in the metagenomes were identified and annotated using the Ribopicker tool (Schmieder et al., 2012) with the Silva 123 SSU database (Quast et al., 2013).

For viral mining, bacterial, archaeal and eukaryotic sequences were removed through end-to-end mapping, allowing a $5 \%$ of mismatch (-N 1 -L 20) against the NCBI non-redundant (NR) database (Nov-2015) using bowtie2 (Langmead and Salzberg, 2012). Viral sequences were then recruited against modified NCBI RefSeq (Release 75) viral proteins, where only amino acid sequences from viruses that do not infect animals (NAV) were considered to build the database, using the UBLAST algorithm (-strand both -accel 0.9) through the USEARCH sequence analysis tool (Edgar, 2010). Recruitment was made for sequences with over $65 \%$ of coverage and an E-value $<1 \times 10^{-3}$ (-query_cov 0.65 -evalue 1e-3). For taxonomic assignment, recruited sequences were aligned against the NAV database using BLASTX (Camacho et al., 2009) and parsed using the lowest common ancestor algorithm trough MEGAN 6 (Huson et al., 2016) (LCA score = 30). The latter displays a graphical representation of abundance for each taxonomic group identified at the family and species levels. Species classification of viral reads, was used to infer the phyla of the putative hosts based on viral RefSeq host information or through a manual search of the publication associated with each viral genome.

To extract putative viral genomes, all metagenomes (48, 58, and $\left.66^{\circ} \mathrm{C}\right)$ were assembled using De Bruijn graphs as implemented in the Spades assembler (Bankevich et al., 2012), followed by gene prediction using Prodigal software (Hyatt et al., 2010) and the recovery of circular contigs over $5 \mathrm{~kb}$ using a Python script (Crits-Christoph et al., 2016). Only sequences over $5 \mathrm{~kb}$ were used in the subsequent analysis because all dsDNA viruses in the databases have genomes over that size. A homology search of the viral predicted proteins by Prokka (Seemann, 2014) was done using BLASTX against the NAV protein database and NCBI nr as described before. Additionally, all contigs over $5 \mathrm{~kb}$ were analyzed using VirSorter (Roux et al., 2015a) against the virome database option.

To quantify the abundance and activity of the retrieved viral genome, reads recruitment from each metagenome and 
metatranscriptome was performed using BWA-MEM (-M), resulting SAM file was parsed by BBmap pileup script (Bushnell B. $)^{1}$.

\section{Phylogenetic Analysis}

The protein inferred sequences of DNA polymerase and major capsid were aligned by Muscle (Edgar, 2004) and MAFFT (Katoh et al., 2002), respectively, using the amino acid substitution model determined by ProtTest 3 (Blosum62+G+F) (Darriba et al., 2011) and modelFinder (LG+F+G4), respectively. The Bayesian Markov chain Monte Carlo method was implemented with MrBayes 3.6 (Ronquist et al., 2012) and MCMC results were summarized with Tracer $1.6^{2}$. MrBayes was run using two independent runs, four chains, 1,500,000 generations and a sampling frequency of 100 with a burn-in value of $33 \%$ until the standard deviations of split frequencies remained below 0.01 .

The maximum likelihood method was implemented with IQtree (-bb 10000 -nm 10000 -bcor 1 -numstop 1000) (Trifinopoulos et al., 2016) using 100 standard bootstrap and 10,000 ultrafast bootstrap to evaluate branch supports. The details of the sequences used for phylogenetic analyses are listed in Supplementary Table S2.

\section{CRISPR/Cas Virotopes}

Assemblies for each temperature, were taxonomically grouped (bins) using the Expectation-Maximization (EM) algorithm implemented in MaxBin 2.0 (Wu et al., 2016). In order to asses the completeness and contamination of each bin, CheckM (Parks et al., 2015) analyses were performed. Finally, the closest genome of each bin was searched using the Tetra Correlation Search (TCS) analysis implemented in Jspecies tool (Richter et al., 2016) with selection criteria of $\mathrm{Z}$ score greater than 0.999 and ANI over 95\% (Konstantinidis et al., 2017).

CRISPR/Cas loci were identified in contigs assigned to Mastigocladus spp. from 48, 58, and $66^{\circ} \mathrm{C}$ assembled metagenomes using CRISPRFinder tool (Grissa et al., 2007). To quantify the activity of the CRISPR loci, reads recruitment from metatranscriptomes for the same temperatures was performed using BWA-MEM (-M), and the resulting SAM file was parsed by BBmap pileup script (Bushnell B.) (see footnote 1) and normalized by total number of reads and length of each loci.

Spacers from CRISPR containing contigs were mapped to viral contigs using bowtie2 (Langmead and Salzberg, 2012) parameters (-end-to-end -very sensitive -N 1). Mapped spacers were manually annotated to the viral predicted proteins in viral contig.

\section{Single Nucleotide Variants (SNVs)}

To call variants occurring in TC-CHP58 populations at the three different metagenome temperatures, LoFreq method (Wilm et al., 2012) was used. SNVs frequencies were quantified in ORFs from TC-CHP58 genome using Bedtools suite (Quinlan and Hall, 2010). The alleles of SNVs present in proto-spacers were visualized in IGV tools for each virotope at each temperature.

${ }^{1}$ sourceforge.net/projects/bbmap/

${ }^{2}$ http://beast.bio.ed.ac.uk/Tracer

\section{RESULTS}

\section{Morphological and Genetic Composition of VLPs}

Transmission electron microscopy (TEM) was applied to identify the VLPs present in the interstitial fluid from microbial mats in Porcelana hot spring. Caudovirus-like particles belonging to Myoviridae, Podoviridae and Siphoviridae families, typically infecting bacteria (Figures 1A-G) were identified. Additionally, filamentous and rod shaped VLPs were detected, that could be associated with Lipothrixviridae and Clavaviridae families, usually infecting archaea (Figures $\mathbf{1 H}-\mathbf{K}$ ). Viral read counts ranged between 0.47 and $0.78 \%$ of the total metagenome reads, and between 0.35 and $3.71 \%$ in the metatranscriptomes (Supplementary Table S1). At all temperatures, viral metagenomic sequences (Figure 2) revealed the dominance of the Order Caudovirales, followed by the Order Megavirales, with $\sim 70 \%$ and $\sim 23 \%$ of the total viral reads, respectively. Metatranscriptomic analysis results (Figure 2) showed a slightly different pattern, with a reduction in Caudovirales with increasing temperature (from $\sim 78 \%$ at $48^{\circ} \mathrm{C}$ to $\sim 57 \%$ at $66^{\circ} \mathrm{C}$ ), whereas Megavirales did the opposite (from $\sim 7 \%$ at $48^{\circ} \mathrm{C}$ to $\sim 36 \%$ at $66^{\circ} \mathrm{C}$ ).

In the metagenomes, Siphoviridae was the most abundant family of Caudovirales, with maximum abundance at $48^{\circ} \mathrm{C}$. Myoviridae members were also well represented with a maximum of $\sim 31 \%$ at $58^{\circ} \mathrm{C}$ and a minimum $(\sim 25 \%)$ at $48^{\circ} \mathrm{C}$. Meanwhile, Podoviridae accounted for just $\sim 8 \%$ at all temperatures (Figure 2). In metatranscriptomes, Siphoviridae increased sixfold with temperature, while Podoviridae and Myoviridae decreased with temperature (fivefold and twofold, respectively).

The Megavirales order was also present, however, at a lower abundance compared to Caudovirales. Megavirales were represented by Phycodnaviridae $(\sim 13 \%)$, Mimiviridae $(\sim 8 \%)$, and Marseilleviridae ( $\sim 2 \%)$ families, remaining constant through all temperatures. Metatranscriptomics showed an increase in abundance of these three virus families with temperature.

\section{Caudovirales Host Assignments}

Porcelana mat communities based on miTAGs were dominated by bacteria $(\sim 96 \%)$, with low abundances of eukarya $(\sim 3 \%)$ and archaea $(\sim 1 \%)$ (Supplementary Table S1). At the phylum level (Figure 3A), bacterial communities were mostly composed of Cyanobacteria oxygenic phototrophs $(33,53$, and $21 \%$ of total rRNA SSU sequences at 48,58 , and $66^{\circ} \mathrm{C}$, respectively) and Chloroflexi anoxygenic phototrophs (higher than Cyanobacteria only at $66^{\circ} \mathrm{C}$, with $35 \%$ of total rRNA SSU sequences). Other representative members of the community were Proteobacteria (5-11\%), Deinococcus-Thermus (2-7\%), Firmicutes (1-17\%), and Bacteroidetes (4-8\%) (Figure 3A).

The host assignment, based on taxonomy from viral reads of the most representative Caudovirales (Figure 3B), showed that viruses putatively infected members of the bacterial phyla Proteobacteria, Cyanobacteria, Actinobacteria, and Firmicutes. Metagenomic data showed that increases in temperature led to an increase in viruses from Actinobacteria and Firmicutes. 


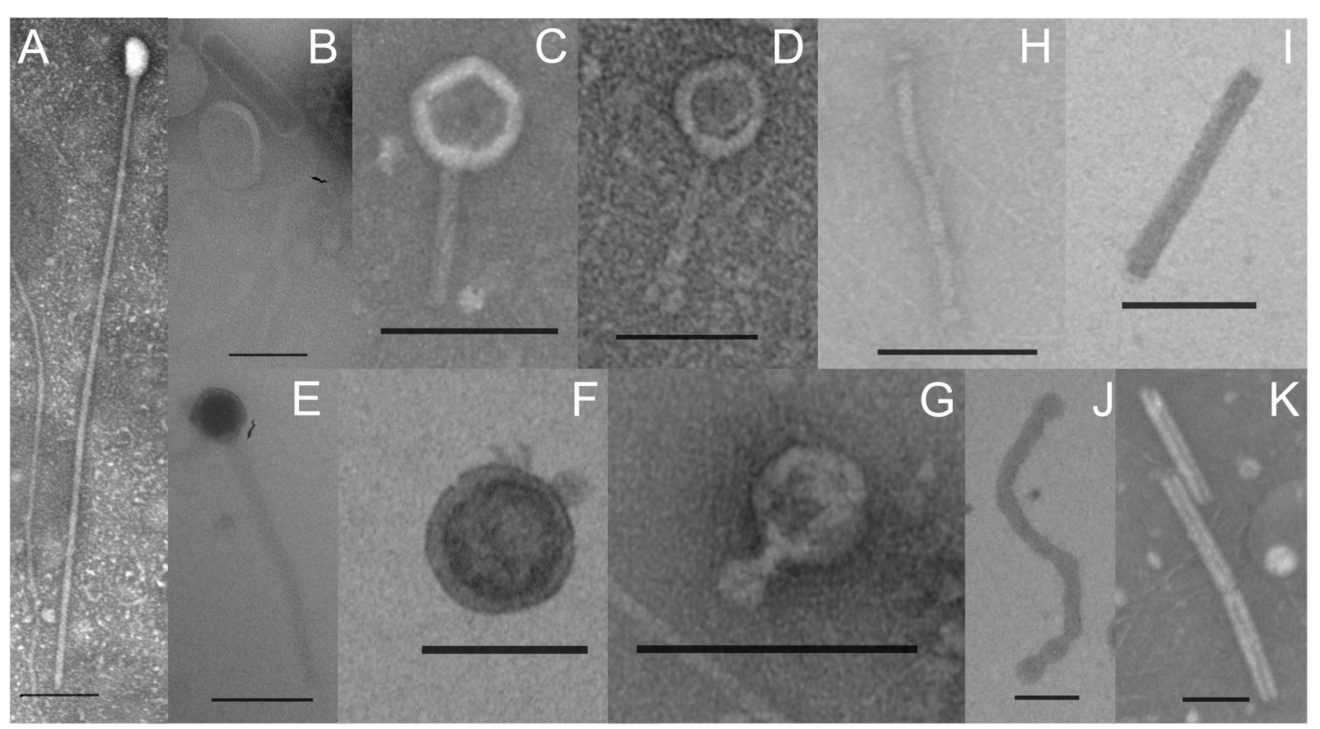

FIGURE 1 | Transmission electronic micrographs of VLPs obtained from the interstitial fluid of phototrophic microbial mats growing between $62^{\circ} \mathrm{C}$ and $42^{\circ} \mathrm{C}$ in Porcelana hot spring. Scale bar: $100 \mathrm{~nm}$. (A-G) Caudovirus-like particles belonging to Myoviridae, Podoviridae, and Siphoviridae families. (H-K) Filamentous and rod shaped VLPS that could be associated with Lipothrixviridae and Clavaviridae families.
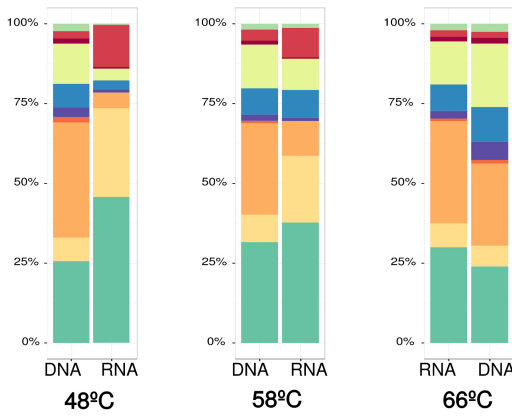

\begin{tabular}{|l|l|l|l|}
\hline Myoviridae & Marseilleviridae & Unclassified viruses \\
\hline Podoviridae & Mimiviridae & Unclassified dsDNA phages \\
\hline Siphoviridae & Phycodnaviridae & Others Families \\
\hline Unclassified Caudovirales & & \\
\hline
\end{tabular}

FIGURE 2 | Relative abundances of viral Families in microbial mats from Porcelana hot spring; standardized by the total number metagenomic reads (DNA), and metatranscriptome (RNA) from each temperature samples.

Additionally, an increase in Cyanobacteria viruses was observed at $58^{\circ} \mathrm{C}$. Viruses from Proteobacteria, Actinobacteria, and Firmicutes were represented by the three Caudovirales families, while viruses from Cyanobacteria were represented by Podoviridae and Myoviridae families only (Supplementary Table S3), where cyanopodovirus and cyanomyovirus reads increase from 31 to $50 \%$ at $48^{\circ} \mathrm{C}$ and from 30 to $45 \%$ at $58^{\circ} \mathrm{C}$, then decrease to 23 to $28 \%$ at $66^{\circ} \mathrm{C}$, respectively.

Metatranscriptomic sequences from Caudovirales potentially infecting Cyanobacteria, were predominant at $48^{\circ} \mathrm{C}$ and $58^{\circ} \mathrm{C}$, with $\sim 90 \%$ and $\sim 74 \%$ of the total viral sequences, respectively. However, cyanophage transcripts abruptly decrease at $66^{\circ} \mathrm{C}$. Cyanophages were exclusively related to the Myoviridae and Podoviridae families (Supplementary Table S3). Reads associated with cyanopodoviruses and cyanomyoviruses gradually decreased with temperature; between 48 and $58^{\circ} \mathrm{C}$, virus reads declined from $95 \%$ and $96 \%$ to $84 \%$ and $89 \%$, respectively. On the other hand, at $66^{\circ} \mathrm{C}$ a more severe decline was observed, to $15 \%$ and $20 \%$, respectively. Conversely, with the reduced representation of Cyanobacteria at $66^{\circ} \mathrm{C}$, other caudovirales transcripts increased, including those that infect Proteobacteria $(\sim 31 \%)$, Firmicutes $(\sim 30 \%)$, and Actinobacteria $(\sim 23 \%)$.

\section{Thermophilic Cyanophage Genome Recovery}

The metagenome assembly recovered 3,912; 2,697; and 2,758 contigs, at $48^{\circ} \mathrm{C}, 58^{\circ} \mathrm{C}$, and $66^{\circ} \mathrm{C}$, respectively. A script search (Crits-Christoph et al., 2016) resulted in 11 circular contigs, possibly indicating complete genomes. Subsequent BLASTP analysis (Camacho et al., 2009) of predicted proteins indicated that only one circular contig had viral hallmark genes, meanwhile nine contigs had genes associated with bacterial mobile genetic elements and one contig remain completely unknown. These hallmark genes are shared by many viruses but are absents 


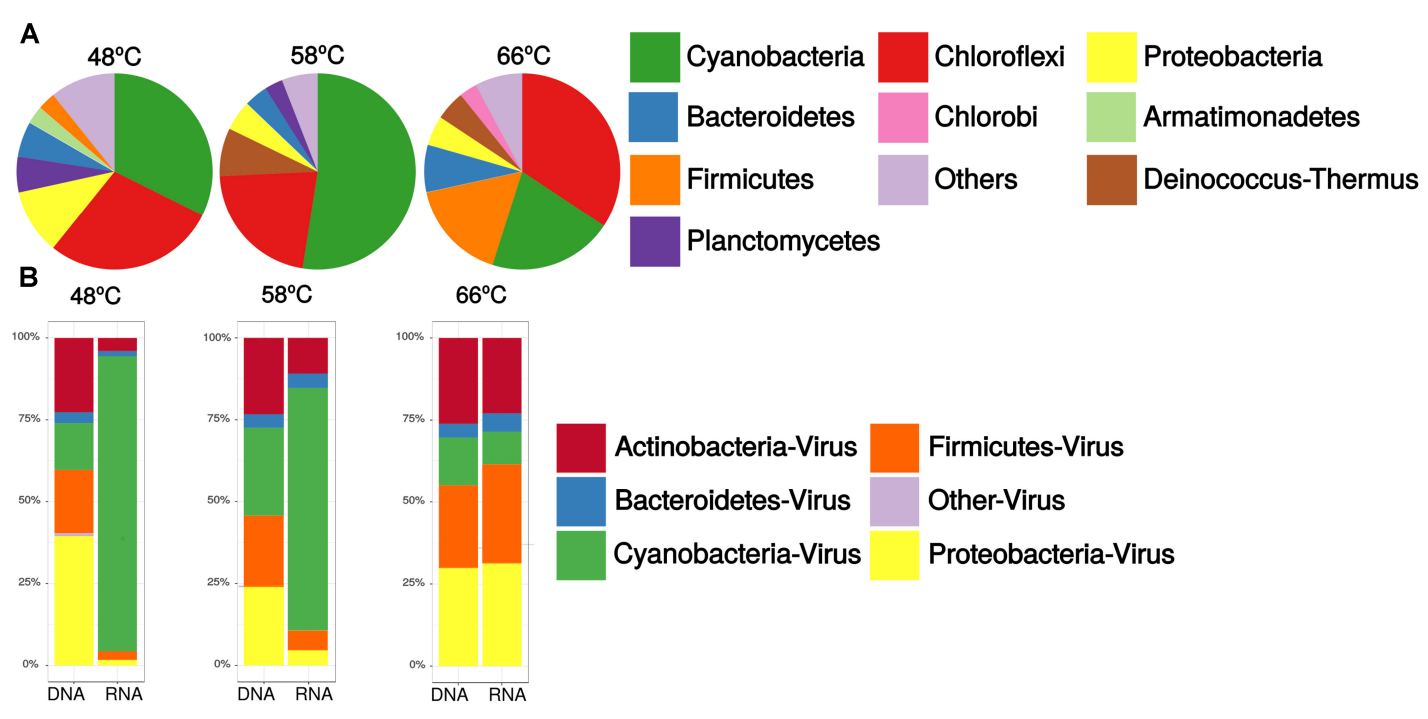

FIGURE 3 | Relative abundances of (A) Bacterial community, to Phylum level, in the microbial mats obtained from 16S miTAGs, standardized by the total number of metagenomic reads (DNA) for each temperature sample, and (B) Caudovirales community at the host Phylum level, obtained from shotgun sequences in metagenomes (DNA) and metatranscriptomes (RNA), standardized by the total number of reads from each temperature sample.

from cellular genomes (Koonin et al., 2006). VirSorter tool analysis (Roux et al., 2015a) confirmed these results, obtaining the same complete putative viral contig from the $58^{\circ} \mathrm{C}$ assembly, 40,740 bp long and $43.9 \%$ of GC content. This contig, TC-CHP58 (Figure 4A), was associated with a Cyanobacterial host. TCCHP58 was present (reads recruitment) over all temperatures in Porcelana hot spring (Figure 5 and Supplementary Figure S1). At $66^{\circ} \mathrm{C}$, TC-CHP58 was sevenfold more abundant than their putative host (measured as Mastigocladus RUBISCO gene abundance); at $48^{\circ} \mathrm{C}$, the virus-host ratio was $1: 1$, and at $58^{\circ} \mathrm{C}$ the host was fourfold more abundant than TC-CHP58. Metatrancriptomic reads also show that TC-CHP58 was active over all temperatures (Figure 5 and Supplementary Figure S2), but with lower transcription levels than the putative host (measured as Mastigocladus RUBISCO gene activity), ranging between 80- and 8-fold lower (Supplementary Table S4). TCCHP58 viral DNA:RNA ratio indicated similar proportions (2.4) at $58^{\circ} \mathrm{C}$, least similar $(552.9)$ at $66^{\circ} \mathrm{C}$; while at $48^{\circ} \mathrm{C}$ the ratio was 10.4 (Supplementary Table S4).

\section{Genomic Features and Organization of TC-CHP58}

Complete protein prediction and annotation of TC-CHP58 using Prokka (Seemann, 2014) and BLASTP revealed 39 putative ORFs, 10 of which were viral core proteins (i.e., capsid and tailrelated proteins, DNA polymerase, Terminase, etc.), 22 had no significant similarities in NCBI nr database, and 4 were present in the database but with unknown function (Table 1).

Blast analysis of the viral genes in TC-CHP58, revealed 25 to $48 \%$ identity (amino acidic level) with proteins from Cyanophage PP, PF-WMP3 and Anabaena phage A-4L, that infect freshwater filamentous Cyanobacteria such as Phormidium, Plectonema, and Anabaena (Table 1). At the nucleotide level, there was almost no similarity to any known sequence except for a short segment of 40 nucleotides, which showed $93 \%$ similarity to a Portal protein gene sequence of Plectonema and Phormidium cyanopodoviruses (Cyanophage PP; NC_022751 and PF-WMP3; NC_009551).

Gene prediction by Prodigal indicated that the TC-CHP58 genome might be structured into two clusters, based on the transcriptional direction and putative gene functions (Figure 4A). The predicted ORFs (Table 1) in the sense strand encode proteins involved in DNA replication and modification, such as DNA polymerase and DNA primase/helicase. Conversely, the ORFs in the antisense strand (Table 1) encode proteins necessary for virion assembly, such as major capsid protein (MCP), tail fiber proteins, internal protein/peptidase, tail tubular proteins, scaffold protein, and portal protein. Moreover, two ORFs in the antisense strand had the best hits to the cyanobacterial hypothetical proteins found in the filamentous cyanobacterium Fischerella (WP_026731322. 1) and the unicellular Gloeobacter (WP_023172199.1).

Additionally, VIRFAM (Lopes et al., 2014) was used to classify TC-CHP58 according to their neck organization (Supplementary Figure S3), being assigned to the Podoviridae Type 3 category with neck structural organization similar to the Enterobacteria phage P22 (Lopes et al., 2014). Hierarchical clustering of neck proteins grouped TC-CHP58 together with the freshwater cyanophages Pf-WMP3 and Pf-WMP4, separating them from marine cyanophages such as P60 and Syn5.

Even when a large number of viral reads were assigned to cyanophages of Myoviridae family, it was not possible to recover any genome of this type. Most of the Myoviridae related contigs only had non-structural genes or hypothetical proteins of unknown function which align with proteins of known 


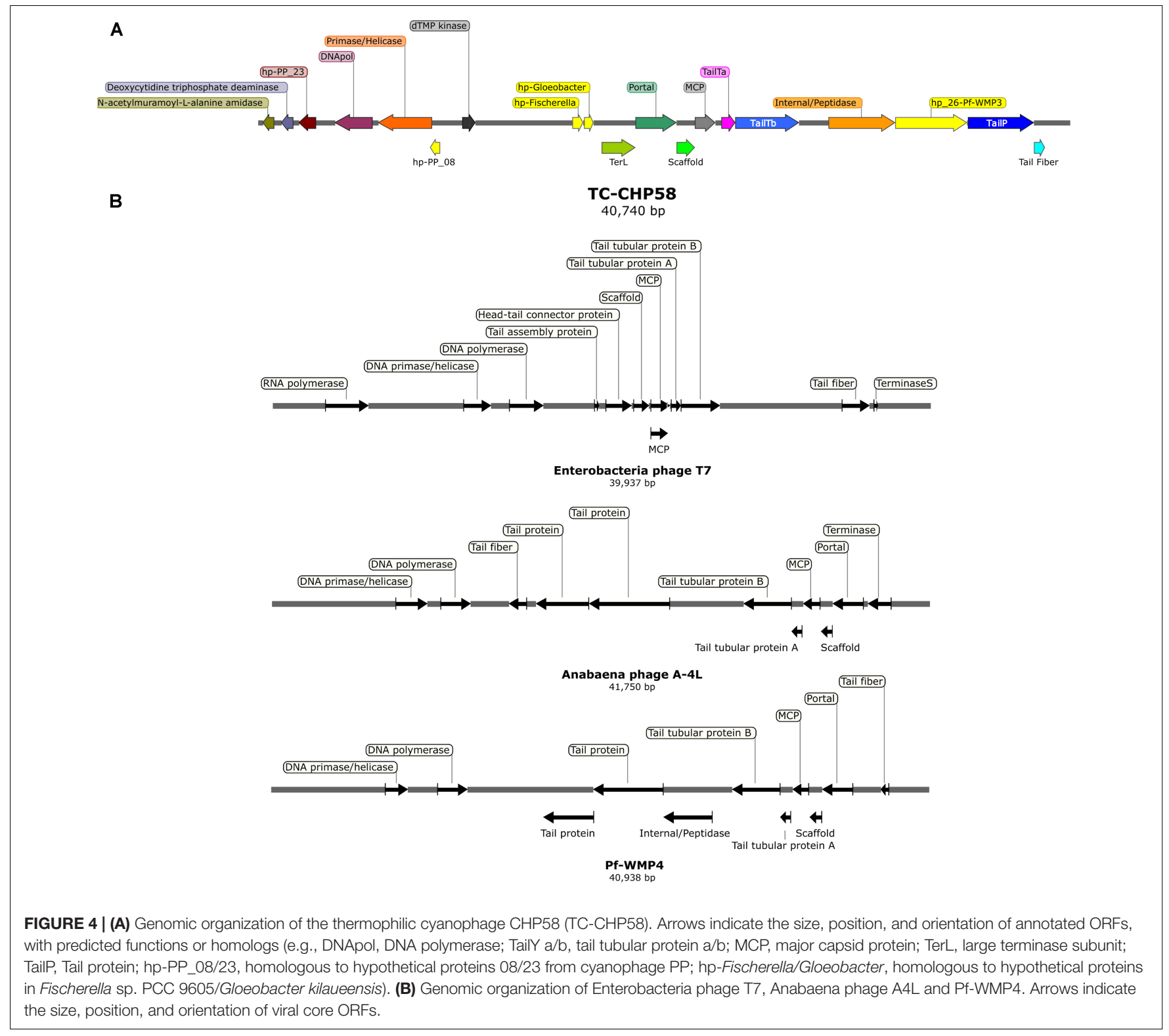

cyanomyoviruses. Here, the absence of hallmark genes from Cyanobacteria related viruses makes their accurate classification as cyanomyoviruses impossible.

\section{Phylogenetic Analysis of Phage TC-CHP58}

To investigate the relationship of the phage TC-CHP58 within the Podoviridae family, the DNApol gene was selected for comparison, using published viral genomes. The analysis included representatives of Picovirinae and Autographivirinae subfamilies, plus all the available DNApol genes from known freshwater podoviruses (Pf-WMP3, PP, Pf-WMP4 and A$4 \mathrm{~L})$ infecting filamentous heterocystous cyanobacteria from the order Nostocales and non-heterocystous from order Oscillatoriales, plus those infecting marine Synechococcus spp. and Prochlorococcus spp. The DNApol tree (Figure 6) showed the phage TC-CHP58 as part of a monophyletic clade with all cyanopodoviruses described as infecting freshwater filamentous cyanobacteria, and more distantly, with the marine cyanopodovirus clade that infects Synechococcus spp. and Prochlorococcus spp. Both cyanophage subgroups are closely related with podoviruses from the Autographivirinae subfamily, which includes all T7 relatives. Furthermore, the phylogeny of the MCP was constructed for freshwater and marine representatives of the Autographivirinae subfamily. The available MCP gene from BHS3 Cyanophage partial genome, that is the only known thermophilic representative within the Podoviridae family, was also included (Zablocki et al., 2017). The MCP tree (Supplementary Figure S4) showed similar results to the DNApol tree (Figure 6), with a monophyletic origin for all freshwater cyanophages infecting 


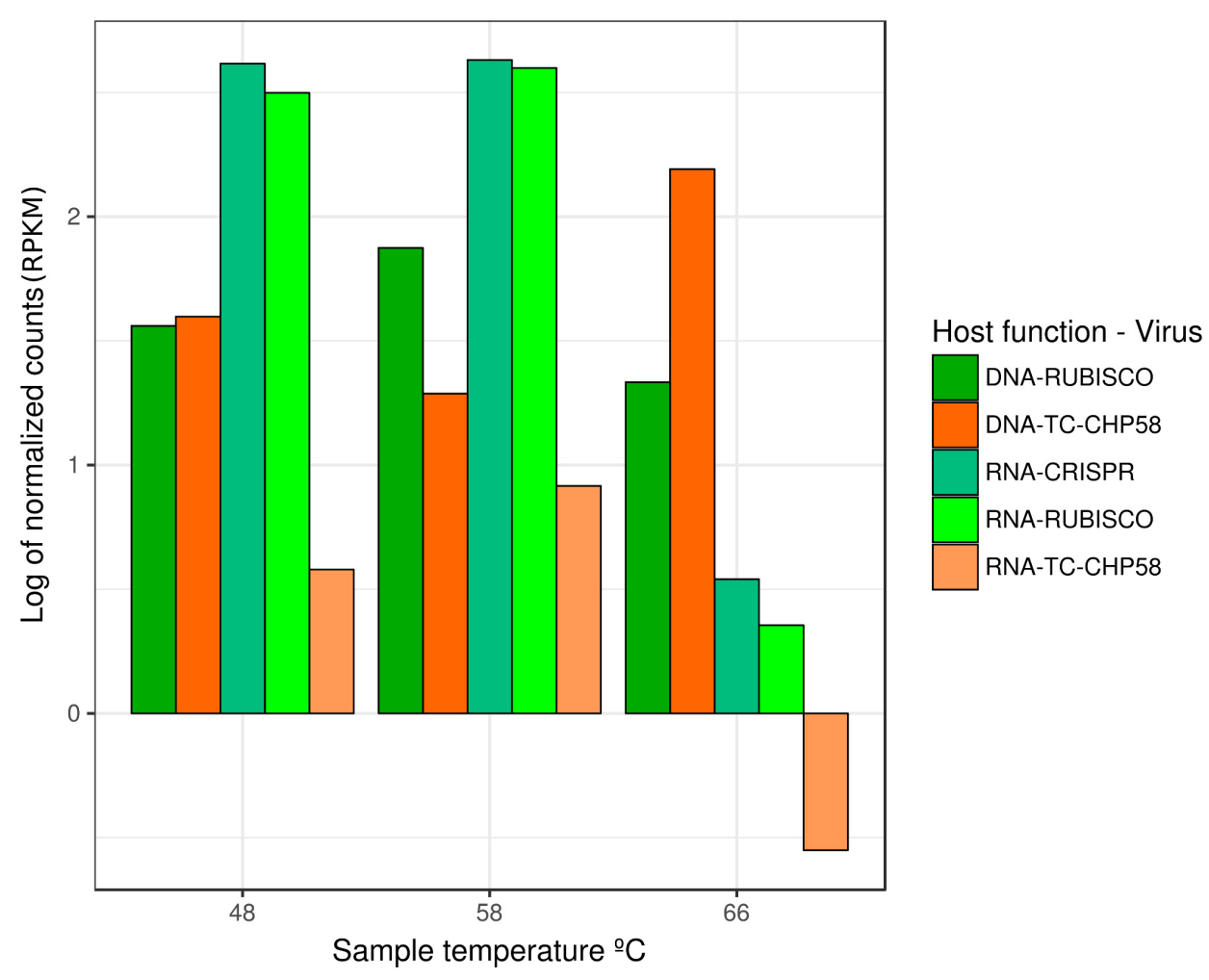

FIGURE 5 | Relative abundance and transcriptomic expression of Mastigocladus spp. CRISPR systems and TC-CHP58. Abundance and expression of Mastigocladus RUBISCO was used as reference of the cyanobacterial presence and metabolic activity. Only specific CRISPR loci with proto-spacers in TC-CHP58 were fully quantified for each temperature. For improved visualization, counts are represented as Log of reads per kilobase million (RPKM).

TABLE 1 | Blastp analysis of predicted CDS from TC-CHP58 of known function against NCBI RefSeq (Release 75) and NR databases.

\begin{tabular}{|c|c|c|c|c|}
\hline Query sequence ID & Subject sequence ID & Identity \% & E-value & Bit Score \\
\hline TC-CHP58_sequence & KF598865.1| [Cyanophage PP] & $93 \%$ & 0.2 & 54.7 \\
\hline TC-CHP58_CDS1 & YP_009042789.1| DNA polymerase [Anabaena phage A-4L] & 29.03 & 4.00E-60 & 223 \\
\hline TC-CHP58_CDS3 & YP_009042786.1| DNA primase/helicase [Anabaena phage A-4L] & 25.21 & $2.00 \mathrm{E}-28$ & 131 \\
\hline TC-CHP58_CDS4 & YP_008766966.1| hypothetical protein PP_08 [Cyanophage PP] & 29.7 & 0.0006 & 47 \\
\hline TC-CHP58_CDS7 & WP_026824764.1| dTMP kinase [Exiguobacterium marinum] & 30.61 & $4.00 \mathrm{E}-22$ & 99.4 \\
\hline TC-CHP58_CDS13 & WP_026731322.1| hypothetical protein [Fischerella sp. PCC 9605] & 34.55 & $7.00 \mathrm{E}-12$ & 69.3 \\
\hline TC-CHP58_CDS14 & WP_023172199.1| hypothetical protein [Gloeobacter kilaueensis] & 42.31 & $4 \mathrm{E}-05$ & 48.1 \\
\hline TC-CHP58_CDS15 & YP_008766995.1| terminase [Cyanophage PP] & 44.39 & $2.00 \mathrm{E}-150$ & 456 \\
\hline TC-CHP58_CDS16 & YP_001285799.1| portal protein [Phormidium phage Pf-WMP3] & 42.96 & 0 & 551 \\
\hline TC-CHP58_CDS17 & YP_009042804.1| scaffold protein [Anabaena phage A-4L] & 30.69 & $1 \mathrm{E}-07$ & 60.8 \\
\hline TC-CHP58_CDS18 & YP_008766991.1| capsid protein [Cyanophage PP] & 48.14 & $4.00 \mathrm{E}-109$ & 335 \\
\hline TC-CHP58_CDS20 & YP_009042802.1| tail tubular protein A [Anabaena phage A-4L] & 29.52 & $3.00 \mathrm{E}-28$ & 116 \\
\hline TC-CHP58_CDS21 & YP_001285795.1| tail tubular protein B [Phormidium phage Pf-WMP3] & 36.49 & 0 & 630 \\
\hline TC-CHP58_CDS24 & YP_009042798.1| internal protein [Anabaena phage A-4L] & 29.86 & $5.00 \mathrm{E}-41$ & 174 \\
\hline TC-CHP58_CDS25 & YP_001285791.1| PfWMP3_26 [Phormidium phage Pf-WMP3] & 28.26 & $5.00 \mathrm{E}-23$ & 117 \\
\hline TC-CHP58_CDS26 & YP_009042796.1| tail protein [Anabaena phage A-4L] & 24.8 & 4.00E-89 & 322 \\
\hline TC-CHP58_CDS32 & WP_038085449.1| N-acetylmuramoyl-L-alanine amidase [Tolypothrix bouteillei] & 46.29 & $3.00 \mathrm{E}-46$ & 160 \\
\hline TC-CHP58_CDS35 & WP_043587103.1| deoxycytidine triphosphate deaminase [Diplosphaera colitermitum] & 44.9 & $2.00 \mathrm{E}-48$ & 167 \\
\hline TC-CHP58_CDS37 & YP_008766981.1| hypothetical protein PP_23 [Cyanophage PP] & 29.92 & 1.00E-21 & 101 \\
\hline
\end{tabular}

filamentous cyanobacteria, emphasizing the division between freshwater and marine cyanobacterial viruses, and their affiliation with T7 phage. The thermophilic representatives of Podoviridae family were located in different branches inside the freshwater clade, with BHS3 more basal than TC-CHP58. 


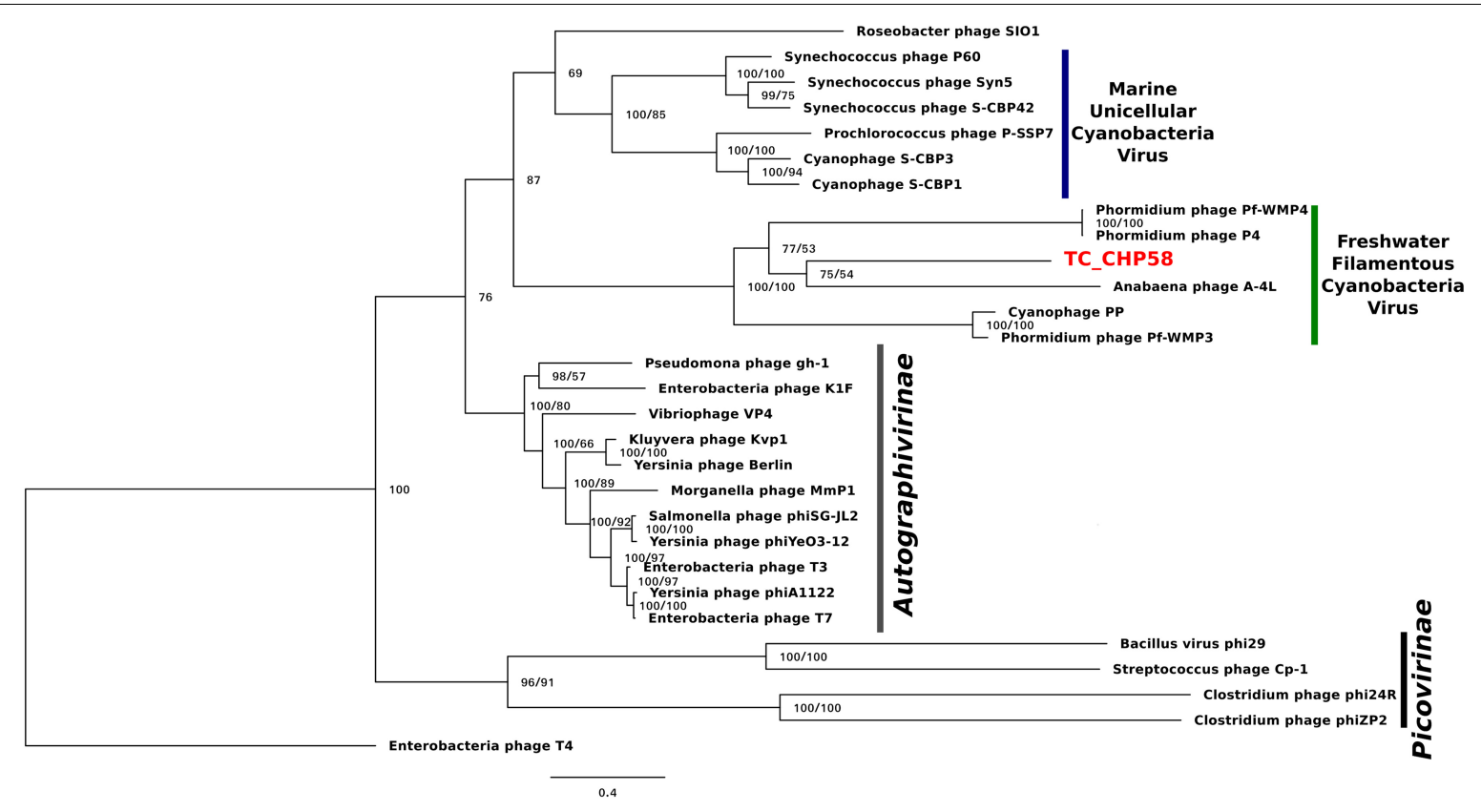

FIGURE 6 | Bayesian inference phylogenetic reconstruction of DNA polymerase I protein of TC-CHP58. Numbers indicate Bayesian posterior probabilities as percentage/ultra-fast bootstrap values. Only UFBoot values over 80 and Bayesian PP over 50 are shown. The sequence characterized in the present study is reported in bold letters. Scale bar: 0.4 amino acid substitutions per site.

\section{CRISPR Arrays on TC-CHP58 Host}

Given the high abundance (Mackenzie et al., 2013; Alcamán et al., 2015) and activity (Alcamán et al., 2015) of cyanobacteria, such as Mastigocladus spp., in Porcelana hot spring (Figure 3A), and in order to confirm the putative host of phage TC-CHP58, CRISPR spacer arrays were identified using the CRISPRFinder tool (Grissa et al., 2007) for seven Mastigocladus spp. Contigs, obtained from metagenome assemblies at $48^{\circ} \mathrm{C}, 58^{\circ} \mathrm{C}$, and $66^{\circ} \mathrm{C}$. Three CRISPR loci were common between all temperatures (48_CRISPR_2, 58_CRISPR_5, and 66_CRISPR_2), while four loci were specific to higher temperatures $\left(58-66^{\circ} \mathrm{C}\right)$ (Table 2). In total, the seven CRISPR loci contain 562 spacers, of which 25 of them had a proto-spacer sequence in the TC-CHP58 genome (Table 2). From the 25 spacers, 19 have a target ORF of known function, such as DNA polymerase, dTMP, portal protein, M23-petidase, tail protein, tail fiber, and deoxycytidine triphosphate deaminase. In general, each CRISPR loci contained spacers against different ORFs on TC-CHP58, or even against different locations on the same ORF. For the 25 spacers, searching the $n t / n r$ database, using BLASTN and BLASTX, showed no similarity to any know sequence. Finally, in order to check if CRISPR systems were active, expression of the seven loci was directly quantified in the three metatranscriptomes. For all temperatures, slightly lower transcript levels were found compared to the Mastigocladus RUBISCO gene (Figure 5).

\section{Identifying Single Nucleotide Variants in TC-CHP58 Genome}

To assess if mismatches between the CRISPR spacer and proto-spacer sequences in TC-CHP58 genome were concealing potential variations in TC-CHP58 populations, a SNV calling was conducted. For this task LoFreq tool was used, as it is high sensitivity and has low false positive rates, lower as $<0.00005 \%$ (Wilm et al., 2012) and higher as 8.3\% (Huang et al., 2015). This approach, together with the use of sequences with qualities over q28 (whose error probability in the base call is $\leq 1.58 \%$ ), allow us to consider these SNVs as real mutations.

A different number of SNVs was found at each temperature. TC-CHP58 showed 1611,930 , and 671 variant sites at $48^{\circ} \mathrm{C}$, $58^{\circ} \mathrm{C}$, and $66^{\circ} \mathrm{C}$, respectively, unevenly distributed throughout the viral genome (Supplementary Figure S5). Considering the three metagenomes, a total of 3212 variable sites were present in the TC-CHP58 genome, with 391 SNVs present over all temperatures (Supplementary Figure S5). Most of the SNVs ( $74 \%$ on average) were located at coding regions on the TCCHP58 genome, with variable rates, ranging from 15 to 0 SNVs for each 100 bp (Supplementary Table S5) over different ORFs.

A detailed analysis of SNVs in CRISPRs proto-spacer sites revealed the presence of these polymorphisms in 14 of the 25 spacer targets, with 13 mismatches and 4 perfect matches (Table 2). The total number of polymorphic sites was 22, with 13 SNVs causing a synonymous substitution and 7 causing a non-synonymous substitution (Table 2).

\section{DISCUSSION}

The study of viruses from thermophilic phototrophic microbial mat communities remains largely unexplored except for a few cases providing limited information on viral presence 


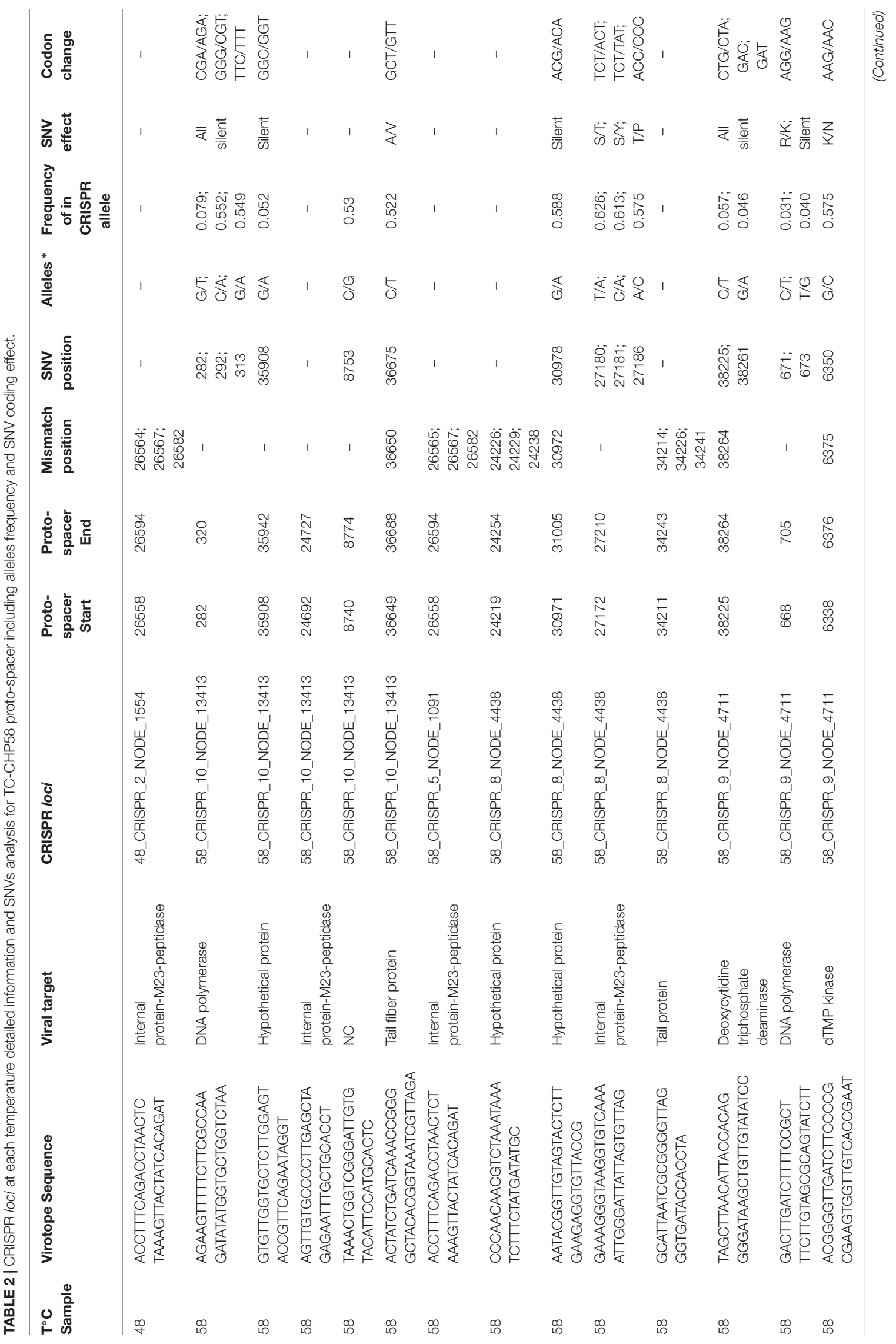




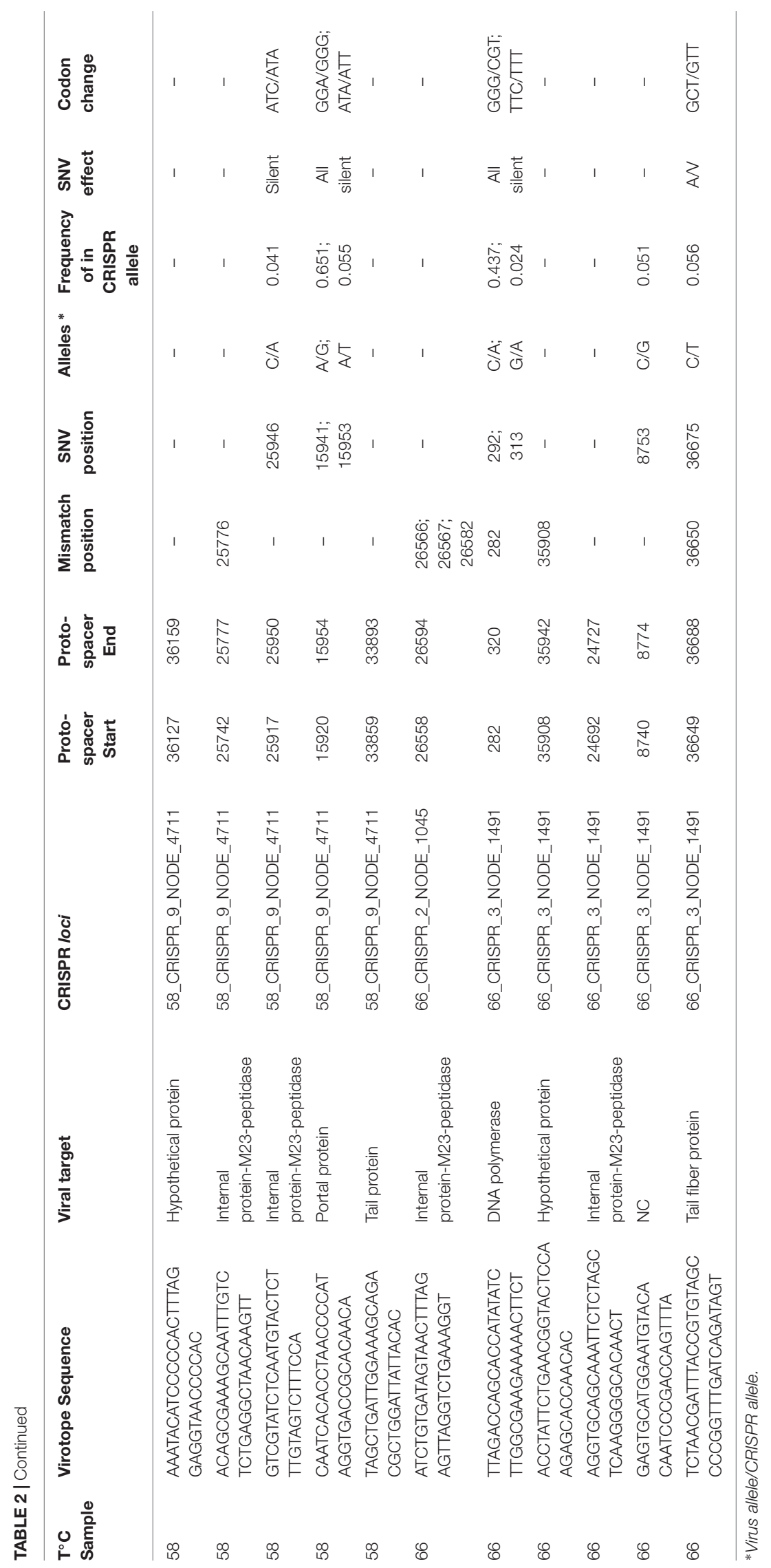


within these communities (Heidelberg et al., 2009; Davison et al., 2016). Thus far, no study has characterized viral composition and activity, or the identity of any complete viral genome. Here, using metagenomic and metatranscriptomic approaches, the composition of the most abundant and active viruses associated with the dominant members of the thermophilic bacterial community have been characterized, describing for the first time a full genome from a thermophilic cyanopodovirus (TC-CHP58). Moreover, the active cross-fire between this new cyanophage and its host is demonstrated, through TC-CHP58 population diversification (SNV), and Mastigocladus spp. CRISPR heterogeneity, as a response to selective pressure from the host defense system and viral predation, respectively.

\section{Active and Ubiquitous Cyanophage-Type Caudovirales in Phototrophic Microbial Mats}

The taxonomic classification of small subunit rRNA (Supplementary Table S1) indicates that the phototrophic mats in Porcelana hot spring are dominated by Bacteria (96\% on average) as commonly observed in other thermophilic phototrophic microbial mats (Inskeep et al., 2013; Bolhuis et al., 2014).

Porcelana microbial mats are mainly built by filamentous representatives of two phototrophic phyla, Cyanobacteria (oxygenic) and Chloroflexi (anoxygenic), with Mastigocladus, Chloroflexus, and Roseiflexus as the main genera, respectively. This is verified by previous surveys carried out by the authors (Mackenzie et al., 2013; Alcamán et al., 2015), as well as investigations from the White Creek, Mushroom, and Octopus hot springs in Yellowstone (Miller et al., 2009; Inskeep et al., 2013; Klatt et al., 2013; Bolhuis et al., 2014), presenting similar $\mathrm{pH}$, thermal gradient and low sulfide concentrations.

Porcelana dominant viruses $(\sim 70 \%$ and $\sim 68 \%$ of metagenomic and metatranscriptomic reads) are from the families Myoviridae, Podoviridae, and Siphoviridae within the Caudovirales Order (Figure 2), which typically infect Bacteria and some non-hyperthermophilic Archaea (Maniloff and Ackermann, 1998). These results were also supported by TEM images (Figure 1). The small decrease in transcripts associated to caudovirales with the increase in temperature is due to the reduction of sequences related to Podovirus and Myovirus families. A plausible explanation, is that at high temperatures some representatives of these families might have a lysogenic lifestyle, then a fraction of them will remain inactive as prophages.

Dominance by Caudovirales was only reported recently from the Brandvlei hot spring, South Africa, a slightly acidic ( $\mathrm{pH}$ 5.7) hot spring with moderate temperature $\left(60^{\circ} \mathrm{C}\right)$ and green microbial mat patches (Zablocki et al., 2017). Previously, the presence of this viral order had only been suggested in moderate thermophilic phototrophic mats from Yellowstone hot springs, through indirect genomic approximations, such as spacers in CRISPR loci, from dominant bacterial members (Heidelberg et al., 2009; Davison et al., 2016) or classifications based on nucleotide motives in metaviromic data (Pride and Schoenfeld, 2008; Davison et al., 2016).

Contributions from megavirus sequences were also identified in Porcelana hot spring (Figure 2), with an average of $\sim 24 \%$ viral metagenomic reads, associated with unicellular eukaryotic hosts such as those from Phycodnaviridae and Mimiviridae families, and also the family Marseilleviridae, but to a lesser extent. The presence of VLPs from these three viral families could not be corroborated through TEM, using the limited available viral fraction $(<0.2 \mu \mathrm{m})$ within the community, as it has been previously documented that nucleocytoplasmic large DNA viruses (NCLDV) particles are only found in larger viral fractions (Pesant et al., 2015). The ubiquity of NCLDVs in hot springs was previously described in a hydrothermal freshwater lake in Yellowstone, with assemblies of genomes from Phycodnaviridae and Mimiviridae (Zhang et al., 2015).

Viral relative abundances and activity reported here can be affected by the lack of replicates at this highly local heterogeneity samples. However, the fact of having three different temperature sampling points for metagenomics and metatranscriptomics, partially compensates the replicate limitation.

Furthermore, many viruses in an environmental sample share a degree of similarity in their genomic sequence, and this intrinsic complexity of metagenomic/metatranscriptomic samples makes difficult to accurately estimate the relative abundances or activity of specific phages at low ranks of taxonomy tree, such as the species level (Sohn et al., 2014). To avoid this problem, our strategy focused on the use of the LCA algorithm at higher taxonomic levels (Order and Family) to classify the viral reads, as well as for the inferred hosts, we use the phylum level.

Virus-host inference in Porcelana phototrophic mats (Figure 3B), demonstrated that the most frequent targets for viral infections were the most dominant and active components of the bacterial communities. Similarly, this is the case in other environments, such as in the human microbiome (Macklaim et al., 2013) and marine communities (Thingstad et al., 2014; Zeigler-Allen et al., 2017). In Porcelana, it is demonstrated that within microbial mats at $48^{\circ} \mathrm{C}$ and $58^{\circ} \mathrm{C}$, cyanophages were among the most active viruses (Figure 3B), as were Cyanobacteria, such as Mastigocladus spp., as exemplified in terms of primary production and nitrogen fixation (Alcamán et al., 2015). The presence of cyanophages has been previously suggested in Yellowstone hot spring phototrophic mats (Heidelberg et al., 2009; Davison et al., 2016), and more recently in the Brandvlei hot spring, South Africa (Zablocki et al., 2017). Heidelberg et al. (2009) found that CRISPR spacers in unicellular cyanobacteria Synechococcus isolates (Syn OS-A and Syn OS-B9) from Octopus Hot Spring, might have 23 known viral targets (lysozyme-related reads, PFAM DUF847) on an independently published metavirome from the same hot spring. More recently, 171 viral contigs associated with the host genus Synechococcus, based on tetranucleotide frequencies, were identified from a microbial mat $\left(60^{\circ} \mathrm{C}\right)$ metavirome from Octopus Spring. The majority of the annotated ORFs on the viral contigs coded for glycoside hydrolases, with lysozyme activity, identifying six CRISPR proto-spacers in those genes (Davison et al., 2016). Even though a taxonomic 
relationship with cyanophages was not confirmed for those proto-spacers containing contigs (Heidelberg et al., 2009; Davison et al., 2016), it provides evidence toward the presence of cyanophages related sequences within these thermophilic mats. The work by Zablocki et al. (2017) reconstructed a $10 \mathrm{~kb}$ partial genome of a new cyanophage (BHS3) from Brandvlei hot spring metavirome, stating that cyanophages appear to be the dominant viruses in the hot spring. The BHS3 contig (MF098555) contains nine ORFs, with the majority of the identified proteins having a close relation to the Cyanophage PP and Phormidium phage Pf-WMP3, which infect freshwater filamentous cyanobacteria Phormidium and Plectonema.

The presence of cyanophages related sequences in thermophilic phototrophic mats is significant, since these viruses are known to play an important role in the evolution of cyanobacteria (Shestakova and Karbysheva, 2015). Cyanophages affect the rate and direction of cyanobacterial evolutionary processes, through the regulation of abundance, population dynamics, and natural community structure. This has been extensively studied and demonstrated for marine environments (Weinbauer and Rassoulzadegan, 2004; Avrani et al., 2011). These cyanophages are proven to play a relevant role in the marine biogeochemical cycles, through the infection and lysis of Cyanobacteria, affecting carbon and nitrogen fixation (Suttle, 2000). Moreover, cyanophages act as a global reservoir of genetic information, as they are vectors for gene transfer, meaning that cyanobacteria can acquire novel attributes within aquatic environments (Kristensen et al., 2010; Chénard et al., 2016).

Caudoviruses were prevalent at $66^{\circ} \mathrm{C}$ in Porcelana, and potentially infecting Firmicutes, Proteobacteria, and Actinobacteria. These phila have also been previously identified in other hot springs at temperatures above $76^{\circ} \mathrm{C}$, such as in Octopus and Bear Paw (Pride and Schoenfeld, 2008). At high temperatures in Porcelana also the phylum Chloroflexi was dominant in the phototrophic mat (Figure 3A). However, viral sequences related to this taxon could not be retrieved, as neither viruses nor viral sequences have been confirmed to infect members of this phylum in any environment. Davison et al. (2016), described viral contigs associated with Roseiflexus sp. from a metavirome from Octopus Spring, but only raw reads are publicly available, without taxonomic assignation. Finally, the recently released IMG/VR database (Paez-Espino et al., 2016) contains three contigs associated by CRISPR spacers to Chloroflexus sp. Here, a BLASTP analyses against RefSeq viral proteins revealed that six of these proteins have a best hit in Mycobacterium phage proteins and one which best hit was a Clavibacter phage protein. These findings, suggest that some of the viral reads classified as Actinobacteria viruses could be instead from unknown Chloroflexi viruses.

\section{Viral Mining Reveals a New Infective Thermophilic Cyanopodovirus Lineage}

Metagenomic surveys of viral genomes are an effective way to detect unknown viruses (Roux et al., 2015a,b; Zhang et al., 2015; Voorhies et al., 2016). In metagenomics, two key elements for virus detection are the presence of viral hallmark genes and the circularity of viral contigs (Roux et al., 2015a,b). Based on these two principles, a complete genome (TC-CHP58) was identified. The genome was represented by a viral contig of $50 \mathrm{~kb}$, which is a typical size for Caudovirales members from the Podoviridae family. The genome size and viral core proteins affiliated with the Podovirus seems to make TC-CHP58 the first report of a full genome of a thermophilic cyanopodovirus. Moreover, the genome organization (Figure 4B) shows a consistent synteny with other cyanopodoviruses, which also lack RNA polymerase inside the T7 supergroup, as described for the viruses Pf-WMP4, Pf-WMP3, Cyanophage PP, Anabaena phage A-4L (Liu et al., 2007, 2008; Zhou et al., 2013; Ou et al., 2015), and the recently reported partial genome of the thermophilic BHS3 cyanophage (Zablocki et al., 2017). Initially, the presence of a singlesubunit RNA polymerase that binds phage specific promoters was considered to be a major, and unique characteristic of the T7 supergroup (Dunn et al., 1983). However, more recently, it has been proposed that podoviruses that share extensive homology with T7, but lack the phage RNA polymerase, are still part of the T7 supergroup, as distant and probably ancient branches (Hardies et al., 2003).

TC-CHP58 presented a genome organization that can be divided into two portions (Figure 4A); with ORFs in the sense strand related to DNA replication and modification, and genes encoded in the antisense strand related to virion assembly. This genome organization is also present in other freshwater T7related podoviruses that infect filamentous cyanobacteria (Liu et al., 2007, 2008; Zhou et al., 2013; Ou et al., 2015), including the thermophilic BHS3 cyanophage (Zablocki et al., 2017). This setup is also similar to the class II and III organization genes in T7-like viruses, where class II genes are responsible for DNA replication and metabolism, and class III genes include structural and maturation genes (Dunn et al., 1983). The VIRFAM analysis of neck protein organization verifies the classification of TC-CHP58 within the Podoviridae family (Supplementary Figure S3), where the Type 3 podovirus encompasses T7-like phages from Autographivirinae subfamilies and several other genera (Lopes et al., 2014). The T7-like classification for TC-CHP58, and other podoviruses that infect freshwater filamentous cyanobacteria, is supported by the organization of the genome into two portions as well as the organization of the neck proteins.

The phylogenetic position of TC-CHP58, based on DNA polymerase I (DNApol) (Figure 6) and MCP (Supplementary Figure S4) predicted proteins, confirm the affiliation of this new virus within the family Podoviridae. Both phylogenetic markers verify the separation between the marine from the freshwater cyanopodoviruses within the T7 family, as previously proposed (Liu et al., 2007; Ou et al., 2015). These results also support the connection between the T7 phages and marine and freshwater cyanopodoviruses (Chen and Lu, 2002; Hardies et al., 2003; Liu et al., 2007; Ou et al., 2015), including TC-CHP58 and BHS3 as representatives of a novel, and potentially globally distributed thermophilic cyanophage lineage. Moreover, this data demonstrates that marine and freshwater cyanopodoviruses, including the thermophilic TC-CHP58, are part of the Autographivirinae subfamily as previously suggested 
for Cyanophage P60 and Roseophage SIO1 (Labonté et al., 2009), both included in this analysis.

In Porcelana, the virus host ratio relating to TC-CHP58 presence was lower than the typical values observed in freshwater environments (Maranger and Bird, 1995), being more similar to other geothermal environments where viral density is typically lower, with 10- to 100-fold less viruses than host cells (LópezLópez et al., 2013). This is expected, considering that there are abundant cyanobacteria in phototrophic mats in Porcelana in comparison with the $10^{4} \mathrm{~mL}^{-1}$ VLPs observed in the water of hot springs (Breitbart et al., 2004). It is also demonstrated that TC-CHP58 presented higher infection efficiency, as revealed by the viral DNA to RNA ratios at lower temperatures $\left(58^{\circ} \mathrm{C}\right.$, then $48^{\circ} \mathrm{C}$ ) with cyanobacteria dominating, while at $66^{\circ} \mathrm{C}$ most of the TC-CHP58 remained inactive (Figure 5). Infection inefficiency is multidimensional, as it initiates from reduced phage adsorption, RNA, DNA, and protein production (Howard-Varona et al., 2017). Thus, the high copy number of TC-CHP 58 DNA at $66^{\circ} \mathrm{C}$ may be due to the persistence of viral DNA (Mengoni et al., 2005) encapsidated extracellularly and intermixed in the microbial mat were the host (Mastigocladus spp.) has a low activity as evidenced by the low expression of the RUBISCO gene and the CRISPR loci. An alternative explanation is the absence, or the diminished presence, of the specific host due to intraspecific diversification as evidenced by the existence of different CRISPR loci at different temperatures. This theory has been proposed for other cyanobacteria, such as Prochlorococcus and Phormidium, where slight differences in fitness, niche, and selective phage predation, explain the coexistence of different populations (Kashtan et al., 2014; Voorhies et al., 2016). The last explanation acquires special importance in light of recent evidence that variations in the structure and function of the heterocyst and differential CRISPR loci are fundamental to diversification of Mastigocladus laminosus (also known as Fischerella thermalis), a cosmopolitan thermophilic cyanobacterium, reinforcing the importance of viral predation (Sano et al., 2018).

\section{CRISPR Spacers Assign Mastigocladus spp. as Putative Hosts for TC-CHP58}

It was possible to verify Mastigocladus spp. as putative hosts for the new cyanopodovirus (TC-CHP58), via the analysis of CRISPR spacers found in the cyanobacteria, recovered from contigs obtained in the same metagenomic datasets. This methodology has been previously used for the identification of novel viruses in hot springs (Heidelberg et al., 2009; Snyder et al., 2010; Davison et al., 2016), as well as in other environments such as acid mines (Andersson and Banfield, 2008), the human microbiome (Stern et al., 2012), as well as sea ice and soils (Sanguino et al., 2015).

Observations from the CRISPR loci over all temperatures (Table 2) indicated that, in general, proto-spacers in the TCCHP58 genome were distributed on coding, and therefore more conserved regions. The expression of seven CRISPR loci (Figure 5), demonstrated the activity of the Mastigocladus spp. defense system against TC-CHP58 over all temperatures. CRISPR arrays are transcribed into a long precursor, containing spacers and repeats, that are processed into small CRISPR
RNAs (crRNAs) by dedicated CRISPR-associated (Cas) endoribonucleases (Brouns et al., 2008). Although it is not possible to measure mature crRNAs, as due to their small size they are likely to be filtered out in RNA-seq libraries, this approximation has been validated using large datasets (Ye and Zhang, 2016).

Despite variations in the number of CRISPR loci observed at each temperature, with $60 \%$ of the total CRISPR loci found in Mastigocladus contigs at $58^{\circ} \mathrm{C}$, the abundance of reads agreed with the abundance of other genes required by these cyanobacteria, such as the RUBISCO gene (Figure 5). This further verified that the loci are from Mastigocladus populations. The different CRISPR loci found over the different temperatures in Porcelana (Table 2), also reinforces the notion that diversification of Mastigocladus is partly due to selective pressure exerted by the predation of viruses, such as TC-CHP58. This theory has been previously put forward for Mastigocladus laminosus in Yellowstone (Sano et al., 2018), and proposed for marine cyanobacteria (Rodriguez-Valera et al., 2009; Kashtan et al., 2014).

Furthermore, each CRISPR loci contains spacers that corresponds to different proto-spacers in the TC-CHP58 genome. Increases in spacer number and diversity against the same virus may explain the increase in interference, whilst decreasing the selection of escape mutants (Staals et al., 2016). Priming mechanisms are the most efficient form of obtaining new spacers (Staals et al., 2016), using a partial match between a pre-existing spacer and the genome of an invading phage to rapidly acquire a new "primed" spacer (Westra et al., 2016). Then, over-representation of spacer sequences in some regions of the TC-CHP58 genome may be related to a site that has already been sampled by the CRISPR-Cas machinery or by other biases such as the secondary structure of phage ssDNA, GC content, and transcriptional patterns (Paez-Espino et al., 2013).

The selection pressure of multiple spacers in Mastigocladus CRISPR loci leads to the emergence of SNVs in the TCCHP58 viral populations (Table 2), which cause mismatches between spacers and proto-spacers, resulting in the attenuation or evasion of the host immune response (Shmakov et al., 2017). It is still possible to utilize mismatched spacers for interference and/or primed adaptation, however, the degree of tolerance to mismatches for interference among the CRISPRCas, varies substantially between different CRISPR-Cas type systems (Shmakov et al., 2017). The variable frequency (0.60.02) of the corresponding spacer SNVs alleles on TC-CHP58 proto-spacers, suggests that some variants are more prevalent throughout the population, regardless of whether the SNV causes a silent mutation. Based on this evidence, it has been proposed that, for other microbial communities, only the most recently acquired spacer can exactly match the virus. This suggests that community stability is driven by compensatory shifts in host resistance levels and virus population structure (Andersson and Banfield, 2008).

The present study describes the underlying viral community structure and activity of thermophilic phototrophic mats. Moreover, abundant virus populations are linked to dominant bacteria, demonstrating the effectiveness of omics approaches in 
estimating the importance and activity of a viral community, in this case with thermophilic cyanophages.

Additionally, the first full genome of a new T7-related virus that infects thermophilic representatives of the cyanobacterium Mastigocladus spp. was here retrieved. This genome may represent a novel, globally present, freshwater thermophilic virus from a new lineage from the Podoviridae family. The latter was strongly suggested by the significant phylogenetic relationship and shared gene organization with the BHS3 cyanophage partial genome (South Africa). Even more, TC-CHP58 proteins also matches several contigs that include common viral hallmarks genes in the IMG/VR database. However, further work is necessary to fully understand the global representation and relevance of this virus, which complete genome is presented here as first reference available.

Finally, the evolutionary arms race between a specific cyanobacteria-cyanophage in the natural environment is exposed, where a there exist a variety of potential scenarios. For instance, host resistance may increase over time forcing the decrease of viral populations, or a specific virus population may occasionally become extremely virulent and cause the crash of the host population as proposed by the "kill the winner" model (Andersson and Banfield, 2008). Alternatively, if CRISPR systems and the diversification of the viral population remain in balance through time, a relatively stable virus and host community may result.

\section{DATA AVAILABILITY STATEMENT}

The datasets generated for this study can be found NCBI as follow: Access to raw data for metagenomes and metatranscriptomes is available through NCBI BioProject ID

\section{REFERENCES}

Alcamán, M., Fernandez, C., Delgado, A., Bergman, B., and Díez, B. (2015). The cyanobacterium Mastigocladus fulfills the nitrogen demand of a terrestrial hot spring microbial mat. ISME J. 9, 2290-2303. doi: 10.1038/ismej. 2015.63

Alcamán, M. E., Alcorta, J., Bergman, B., Vásquez, M., Polz, M., and Díez, B. (2017). Physiological and gene expression responses to nitrogen regimes and temperatures in Mastigocladus sp. strain CHP1, a predominant thermotolerant cyanobacterium of hot springs. Syst. Appl. Microbiol. 40, 102-113. doi: 10.1016/ j.syapm.2016.11.007

Andersson, A. F., and Banfield, J. F. (2008). Virus population dynamics and acquired virus resistance in natural microbial communities. Science (80-) 320, 1047-1050. doi: 10.1126/science. 1157358

Avrani, S., Wurtzel, O., Sharon, I., Sorek, R., and Lindell, D. (2011). Genomic island variability facilitates Prochlorococcus-virus coexistence. Nature 474, 604-608. doi: 10.1038/nature10172

Bankevich, A., Nurk, S., Antipov, D., Gurevich, A. A., Dvorkin, M., Kulikov, A. S., et al. (2012). SPAdes: a new genome assembly algorithm and its applications to single-cell sequencing. J. Comput. Biol. 19, 455-477. doi: 10.1089/cmb.2012. 0021

Bhaya, D., Grossman, A. R., Steunou, A.-S., Khuri, N., Cohan, F. M., Hamamura, N., et al. (2007). Population level functional diversity in a microbial community revealed by comparative genomic and metagenomic analyses. ISME J. 1, 703-713. doi: 10.1038/ismej.2007.46

Bolduc, B., Shaughnessy, D. P., Wolf, Y. I., Koonin, E. V., Roberto, F. F., Young, M. (2012). Identification of novel positive-strand RNA viruses by metagenomic
PRJNA382437. https://www.ncbi.nlm.nih.gov/bioproject/?term= PRJNA382437. The genome of TC-CHP58 has the GenBank accession number KY888885. Contigs containing CRISPRs loci have been submitted to NCBI with GenBank accession numbers MG734911 to MG734917.

\section{AUTHOR CONTRIBUTIONS}

SG-L and BD conceived and designed the experiments. SG-L, OS, and FP performed the experiments. SG-L, CP-A, OS, FP, and BD analyzed the data. SG-L, CP-A, and BD wrote the paper.

\section{FUNDING}

This work was financially supported by Ph.D. scholarships CONICYT $N^{\circ} 21130667$ and 21172022, and CONICYT grant FONDECYT $\mathrm{N}^{\circ} 1150171$. Sequencing was funded by Spanish grant CTM2013-48292-C3-1-R.

\section{ACKNOWLEDGMENTS}

We are grateful to Huinay Scientific Field Station for making our work in the Porcelana hot spring possible.

\section{SUPPLEMENTARY MATERIAL}

The Supplementary Material for this article can be found online at: https://www.frontiersin.org/articles/10.3389/fmicb. 2018.02039/full\#supplementary-material

analysis of archaea-dominated Yellowstone hot springs. J. Virol. 86, 5562-5573. doi: 10.1128/JVI.07196-11

Bolduc, B., Wirth, J. F., Mazurie, A., and Young, M. J. (2015). Viral assemblage composition in Yellowstone acidic hot springs assessed by network analysis. ISME J. 9, 1-16. doi: 10.1038/ismej.2015.28

Bolhuis, H., Cretoiu, M. S., and Stal, L. J. (2014). Molecular ecology of microbial mats. FEMS Microbiol. Ecol. 90, 335-350.

Breitbart, M., Wegley, L., Leeds, S., Rohwer, F., and Schoenfeld, T. (2004). Phage community dynamics in hot springs. Appl. Environ. Microbiol. 70, 1633-1640. doi: 10.1128/AEM.70.3.1633-1640.2004

Brouns, S. J. J., Jore, M. M., Lundgren, M., Westra, E. R., Slijkhuis, R. J. H., Snijders, A. P. L., et al. (2008). Small CRISPR RNAs guide antiviral defense in prokaryotes. Science (80-) 321:960 LP-964.

Camacho, C., Coulouris, G., Avagyan, V., Ma, N., Papadopoulos, J., Bealer, K., et al. (2009). BLAST plus: architecture and applications. BMC Bioinformatics 10:1. doi: 10.1186/1471-2105-10-421

Chen, F., and Lu, J. (2002). Genomic sequence and evolution of marine cyanophage P60: a new insight on lytic and lysogenic phages genomic sequence and evolution of marine cyanophage P60: a new insight on lytic and lysogenic phages. Appl. Environ. Microbiol. 68, 2589-2594. doi: 10.1128/AEM.68.5.25892594.2002

Chénard, C., Wirth, J. F., and Suttle, C. A. (2016). Viruses infecting a freshwater filamentous cyanobacterium (Nostoc sp.) encode a functional CRISPR array and a proteobacterial DNA polymerase B. mBio 7:e0667-16. doi: 10.1128/mBio. 00667-16

Cole, J. K., Peacock, J. P., Dodsworth, J. A., Williams, A. J., Thompson, D. B., Dong, H. L., et al. (2013). Sediment microbial communities in Great Boiling Spring 
are controlled by temperature and distinct from water communities. ISME J. 7, 718-729. doi: 10.1038/ismej.2012.157

Crits-Christoph, A., Gelsinger, D. R., Ma, B., Wierzchos, J., Ravel, J., Davila, A., et al. (2016). Functional interactions of archaea, bacteria and viruses in a hypersaline endolithic community. Environ. Microbiol. 18, 2064-2077. doi: 10.1111/14622920.13259

Darriba, D., Taboada, G. L., and Posada, D. (2011). ProtTest 3: fast selection of best-fit models of protein evolution. Bioinformatics 27, 1164-1165. doi: 10.1093/ bioinformatics/btr088

Davison, M., Treangen, T. J., Koren, S., Pop, M., and Bhaya, D. (2016). Diversity in a polymicrobial community revealed by analysis of viromes, endolysins and CRISPR spacers. PLoS One 11:e0160574. doi: 10.1371/journal.pone.0160574

Diemer, G. S., and Stedman, K. M. (2012). A novel virus genome discovered in an extreme environment suggests recombination between unrelated groups of RNA and DNA viruses A novel virus genome discovered in an extreme environment suggests recombination between unrelated groups of RNA and DNA virus. Biol. Direct. 7, 1-14. doi: 10.1186/1745-6150-7-13

Dunn, J. J., Studier, F. W., and Gottesman, M. (1983). Complete nucleotide sequence of bacteriophage T7 DNA and the locations of T7 genetic elements. J. Mol. Biol. 166, 477-535. doi: 10.1016/S0022-2836(83)80282-4

Edgar, R. C. (2004). MUSCLE: Multiple sequence alignment with high accuracy and high throughput. Nucleic Acids Res. 32, 1792-1797. doi: 10.1093/nar/gkh340

Edgar, R. C. (2010). Search and clustering orders of magnitude faster than BLAST. Bioinformatics 26, 2460-2461. doi: 10.1093/bioinformatics/btq461

Grissa, I., Vergnaud, G., and Pourcel, C. (2007). CRISPRFinder: a web tool to identify clustered regularly interspaced short palindromic repeats. Nucleic Acids Res. 35, 52-57. doi: 10.1093/nar/gkm360

Hardies, S. C., Comeau, A. M., Serwer, P., and Suttle, C. A. (2003). The complete sequence of marine bacteriophage VpV262 infecting Vibrio parahaemolyticus indicates that an ancestral component of a T7 viral supergroup is widespread in the marine environment. Virology 310, 359-371. doi: 10.1016/S0042-6822(03)00172-7

Heidelberg, J. F., Nelson, W. C., Schoenfeld, T., and Bhaya, D. (2009). Germ warfare in a microbial mat community: CRISPRs provide insights into the coevolution of host and viral genomes. PLoS One 4:e4169. doi: 10.1371/journal. pone.0004169

Howard-Varona, C., Roux, S., Dore, H., Solonenko, N. E., Holmfeldt, K., Markillie, L. M., et al. (2017). Regulation of infection efficiency in a globally abundant marine Bacteriodetes virus. ISME J. 11, 284-295. doi: 10.1038/ismej.2016.81

Huang, H. W., Mullikin, J. C., and Hansen, N. F. (2015). Evaluation of variant detection software for pooled next-generation sequence data. BMC Bioinformatics 16:235. doi: 10.1186/s12859-015-0624-y

Huson, D. H., Beier, S., Flade, I., Górska, A., El-Hadidi, M., Mitra, S., et al. (2016). MEGAN Community edition - Interactive exploration and analysis of largescale microbiome sequencing data. PLoS Comput. Biol. 12:e4957. doi: 10.1371/ journal.pcbi.1004957

Hyatt, D., Chen, G.-L., Locascio, P. F., Land, M. L., Larimer, F. W., and Hauser, L. J. (2010). Prodigal: prokaryotic gene recognition and translation initiation site identification. BMC Bioinformatics 11:119. doi: 10.1186/1471-2105-11-119

Inskeep, W. P., Jay, Z. J., Tringe, S. G., Herrgård, M. J., and Rusch, D. B. (2013). The YNP metagenome project: environmental parameters responsible for microbial distribution in the yellowstone geothermal ecosystem. Front. Microbiol. 4:67. doi: $10.3389 /$ fmicb.2013.00067

Jonker, C. Z., van Ginkel, C., and Olivier, J. (2013). Association between physical and geochemical characteristics of thermal springs and algal diversity in Limpopo Province, South Africa. Water SA 2013, 95-104. doi: 10.4314/wsa. v39i1.10

Kashtan, N., Roggensack, S. E., Rodrigue, S., Thompson, J. W., Biller, S. J., Coe, A., et al. (2014). Single-cell genomics reveals hundreds of coexisting subpopulations in wild Prochlorococcus. Science (80- ) 344, 416-420. doi: 10. 1126/science. 1248575

Katoh, K., Misawa, K., Kuma, K., and Miyata, T. (2002). MAFFT: a novel method for rapid multiple sequence alignment based on fast Fourier transform. Nucleic Acids Res. 30, 3059-3066. doi: 10.1093/nar/gkf436

Klatt, C. G., Inskeep, W. P., Herrgard, M. J., Jay, Z. J., Rusch, D. B., Tringe, S. G., et al. (2013). Community structure and function of high-temperature chlorophototrophic microbial mats inhabiting diverse geothermal environments. Front. Microbiol. 4:e106. doi: 10.3389/fmicb.2013. 00106

Klatt, C. G., Wood, J. M., Rusch, D. B., Bateson, M. M., Hamamura, N., Heidelberg, J. F., et al. (2011). Community ecology of hot spring cyanobacterial mats: predominant populations and their functional potential. ISME J. 5, 1262-1278. doi: 10.1038/ismej.2011.73

Konstantinidis, K. T., Rosselló-Móra, R., and Amann, R. (2017). Uncultivated microbes in need of their own taxonomy. ISME J. 11, 2399-2406. doi: 10.1038/ ismej.2017.113

Koonin, E. V., Senkevich, T. G., and Dolja, V. V. (2006). The ancient virus world and evolution of cells. Biol. Direct. 1:27. doi: 10.1186/1745-6150-1-27

Kristensen, D. M., Mushegian, A. R., Dolja, V. V., and Koonin, E. V. (2010). New dimensions of the virus world discovered through metagenomics. Trends Microbiol. 18, 11-19. doi: 10.1016/j.tim.2009.11.003

Labonté, J. M., Reid, K. E., Suttle, C. A., Labont, J. M., Reid, K. E., and Suttle, C. A. (2009). Phylogenetic analysis indicates evolutionary diversity and environmental segregation of marine podovirus DNA polymerase gene sequences. Appl. Environ. Microbiol. 75, 3634-3640. doi: 10.1128/AEM. 02317-08

Langmead, B., and Salzberg, S. L. (2012). Fast gapped-read alignment with Bowtie 2. Nat. Methods 9, 357-359. doi: 10.1038/nmeth.1923

Lin, K.-H., Liao, B.-Y., Chang, H.-W., Huang, S.-W., Chang, T.-Y., Yang, C.-Y., et al. (2015). Metabolic characteristics of dominant microbes and key rare species from an acidic hot spring in Taiwan revealed by metagenomics. BMC Genomics 16:1029. doi: 10.1186/s12864-015-2230-9

Liu, X., Kong, S., Shi, M., Fu, L., Gao, Y., and An, C. (2008). Genomic analysis of freshwater cyanophage Pf-WMP3 infecting cyanobacterium Phormidium foveolarum: the conserved elements for a phage. Microb. Ecol. 56, 671-680. doi: 10.1007/s00248-008-9386-7

Liu, X., Shi, M., Kong, S., Gao, Y., and An, C. (2007). Cyanophage Pf-WMP4, a T7like phage infecting the freshwater cyanobacterium Phormidium foveolarum: complete genome sequence and DNA translocation. Virology 366, 28-39. doi: 10.1016/j.virol.2007.04.019

Liu, Z., Klatt, C. G., Wood, J. M., Rusch, D. B., Ludwig, M., Wittekindt, N., et al. (2011). Metatranscriptomic analyses of chlorophototrophs of a hot-spring microbial mat. ISME J. 5, 1279-1290. doi: 10.1038/ismej.2011.37

Logares, R., Sunagawa, S., Salazar, G., Cornejo-Castillo, F. M., Ferrera, I., Sarmento, H., et al. (2014). Metagenomic 16S rDNA Illumina tags are a powerful alternative to amplicon sequencing to explore diversity and structure of microbial communities. Environ. Microbiol. 16, 2659-2671. doi: 10.1111/ 1462-2920.12250

Lopes, A., Tavares, P., Petit, M. A., Guérois, R., and Zinn-Justin, S. (2014). Automated classification of tailed bacteriophages according to their neck organization. BMC Genomics 15:1027. doi: 10.1186/1471-2164-15-1027.

López-López, O., Cerdán, M., and González-Siso, M. (2013). Hot spring metagenomics. Life 3, 308-320. doi: 10.3390/life3020308

Mackenzie, R., Pedrós-Alió, C., and Díez, B. (2013). Bacterial composition of microbial mats in hot springs in Northern Patagonia: variations with seasons and temperature. Extremophiles 17, 123-136. doi: 10.1007/s00792-012-0499-z

Macklaim, J. M., Fernandes, A. D., Di Bella, J. M., Hammond, J.-A., Reid, G., and Gloor, G. B. (2013). Comparative meta-RNA-seq of the vaginal microbiota and differential expression by Lactobacillus iners in health and dysbiosis. Microbiome 1:12. doi: 10.1186/2049-2618-1-12

Maniloff, J., and Ackermann, H. W. (1998). Taxonomy of bacterial viruses: establishment of tailed virus genera and the order Caudovirales. Arch. Virol. 143, 2051-2063. doi: 10.1007/s007050050442

Maranger, R., and Bird, D. F. (1995). Viral abundance in aquatic systems: a comparison between marine and fresh waters. Mar. Ecol. Prog. Ser. 121, 217226. doi: $10.3354 /$ meps 121217

Martin, M. (2011). Cutadapt removes adapter sequences from high-throughput sequencing reads. EMBnet. J. 17, 10. doi: 10.14806/ej.17.1.200

Mengoni, A., Tatti, E., Decorosi, F., Viti, C., Bazzicalupo, M., and Giovannetti, L. (2005). Comparison of 16S rRNA and 16S rDNA T-RFLP approaches to study bacterial communities in soil microcosms treated with chromate as perturbing agent. Microb. Ecol. 50, 375-384. doi: 10.1007/s00248-004-0222-4

Miller, S. R., Purugganan, M., and Curtis, S. E. (2006). Molecular population genetics and phenotypic diversification of two populations of the thermophilic 
cyanobacterium Mastigocladus laminosus. Appl. Environ. Microbiol. 72, 27932800. doi: 10.1128/AEM.72.4.2793-2800.2006

Miller, S. R., Strong, A. L., Jones, K. L., and Ungerer, M. C. (2009). Barcoded pyrosequencing reveals shared bacterial community properties along the temperature gradients of two alkaline hot springs in Yellowstone National Park. Appl. Environ. Microbiol. 75, 4565-4572. doi: 10.1128/AEM.02792-08

Ou, T., Liao, X. Y., Gao, X. C., Xu, X. D., and Zhang, Q. Y. (2015). Unraveling the genome structure of cyanobacterial podovirus $\mathrm{A}-4 \mathrm{~L}$ with long direct terminal repeats. Virus Res. 203, 4-9. doi: 10.1016/j.virusres.2015.03.012

Paez-Espino, D., Eloe-Fadrosh, E. A., Pavlopoulos, G. A., Thomas, A. D., Huntemann, M., Mikhailova, N., et al. (2016). Uncovering Earth's virome. Nature 536, 425-430. doi: 10.1038/nature19094

Paez-Espino, D., Morovic, W., Sun, C. L., Thomas, B. C., Ueda, K. I., Stahl, B., et al. (2013). Strong bias in the bacterial CRISPR elements that confer immunity to phage. Nat. Commun. 4, 1430-1437. doi: 10.1038/ncomms2440

Parks, D. H., Imelfort, M., Skennerton, C. T., Hugenholtz, P., and Tyson, G. W. (2015). CheckM: assessing the quality of microbial genomes recovered from. Cold Spring Harb. Lab. Press Method 1, 1-31.

Pawlowski, A., Rissanen, I., Bamford, J. K. H., Krupovic, M., and Jalasvuori, M. (2014). Gammasphaerolipovirus, a newly proposed bacteriophage genus, unifies viruses of halophilic archaea and thermophilic bacteria within the novel family Sphaerolipoviridae. Arch. Virol. 159, 1541-1554. doi: 10.1007/s00705013-1970-6

Pesant, S., Not, F., Picheral, M., Kandels-Lewis, S., Le Bescot, N., Gorsky, G., et al. (2015). Open science resources for the discovery and analysis of Tara Oceans data. Sci. Data 2:150023. doi: 10.1038/sdata.2015.23

Prangishvili, D., and Garrett, R. A. (2004). Exceptionally diverse morphotypes and genomes of crenarchaeal hyperthermophilic viruses. Biochem. Soc. Trans. 32, 204-208. doi: 10.1042/bst0320204

Pride, D. T., and Schoenfeld, T. (2008). Genome signature analysis of thermal virus metagenomes reveals Archaea and thermophilic signatures. BMC Genomics 9:420. doi: 10.1186/1471-2164-9-420

Quast, C., Pruesse, E., Yilmaz, P., Gerken, J., Schweer, T., Yarza, P., et al. (2013). The SILVA ribosomal RNA gene database project: improved data processing and web-based tools. Nucleic Acids Res. 41, 590-596. doi: 10.1093/nar/ gks1219

Quinlan, A. R., and Hall, I. M. (2010). BEDTools: a flexible suite of utilities for comparing genomic features. Bioinformatics 26, 841-842. doi: 10.1093/ bioinformatics/btq033

Rachel, R., Bettstetter, M., Hedlund, B. P., Häring, M., Kessler, A., Stetter, K. O., et al. (2002). Remarkable morphological diversity of viruses and viruslike particles in hot terrestrial environments. Arch. Virol. 147, 2419-2429. doi: 10.1007/s00705-002-0895-2

Redder, P., Peng, X., Brügger, K., Shah, S. A., Roesch. F., Greve, B., et al. (2009). Four newly isolated fuselloviruses from extreme geothermal environments reveal unusual morphologies and a possible interviral recombination mechanism. Environ. Microbiol. 11, 2849-2862. doi: 10.1111/j.1462-2920.2009. 02009.x

Richter, M., Rosselló-Móra, R., Glöckner, F., and Peplies, J. (2016). JSpeciesWS: a web server for prokaryotic species circumscription based on pairwise genome comparison. Bioinformatics 32, 929-931. doi: 10.1093/bioinformatics/ btv681

Rodriguez-Valera, F., Martin-Cuadrado, A.-B., Rodriguez-Brito, B., Pasiæ, L., Thingstad, T. F., Rohwer, F., et al. (2009). Explaining microbial population genomics through phage predation. Nat. Rev. Microbiol. 7, 828-836. doi: 10. 1038/nrmicro2235

Ronquist, F., Teslenko, M., Van Der Mark, P., Ayres, D. L., Darling, A., Höhna, S., et al. (2012). Mrbayes 3.2: Efficient bayesian phylogenetic inference and model choice across a large model space. Syst. Biol. 61, 539-542. doi: 10.1093/sysbio/ sys029

Roux, S., Enault, F., Hurwitz, B. L., and Sullivan, M. B. (2015a). VirSorter: mining viral signal from microbial genomic data. PeerJ 3:e985. doi: 10.7717/peerj.985

Roux, S., Hallam, S. J., Woyke, T., and Sullivan, M. B. (2015b). Viral dark matter and virus-host interactions resolved from publicly available microbial genomes. Elife 4:e08490. doi: 10.7554/eLife.08490

Sanguino, L., Franqueville, L., Vogel, T. M., and Larose, C. (2015). Linking environmental prokaryotic viruses and their host through CRISPRs. FEMS Microbiol. Ecol. 91, 1-9. doi: 10.1093/femsec/fiv046
Sano, E. B., Wall, C. A., Hutchins, P. R., and Miller, S. R. (2018). Ancient balancing selection on heterocyst function in a cosmopolitan cyanobacterium. Nat. Ecol. Evol. 2, 510-519. doi: 10.1038/s41559-017-0435-9

Schmieder, R., and Edwards, R. (2011). Quality control and preprocessing of metagenomic datasets. Bioinformatics 27, 863-864. doi: 10.1093/ bioinformatics/btr026

Schmieder, R., Lim, Y. W., and Edwards, R. (2012). Identification and removal of ribosomal RNA sequences from metatranscriptomes. Bioinformatics 28, 433-435. doi: 10.1093/bioinformatics/btr669

Schoenfeld, T., Patterson, M., Richardson, P. M., Wommack, K. E., Young, M., and Mead, D. (2008). Assembly of viral metagenomes from yellowstone hot springs. Appl. Environ. Microbiol. 74, 4164-4174. doi: 10.1128/AEM.02598-07

Seemann, T. (2014). Prokka: rapid prokaryotic genome annotation. Bioinformatics 30, 2068-2069. doi: 10.1093/bioinformatics/btu153

Shestakova, S. V., and Karbysheva, E. A. (2015). The role of viruses in the evolution of Cyanobacteria. Biol. Bull. Rev. 5, 527-537. doi: 10.1134/S20790864150 60079

Shmakov, S. A., Sitnik, V., Makarova, K. S., Wolf, Y. I., Severinov, K. V., and Koonin, E. (2017). The CRISPR spacer space is dominated by crossm the CRISPR spacer space is dominated. mBio 8, 1-18. doi: $10.1128 / \mathrm{mBio}$. 01397-17

Snyder, J. C., Bateson, M. M., Lavin, M., and Young, M. J. (2010). Use of cellular CRISPR (clusters of regularly interspaced short palindromic repeats) spacerbased microarrays for detection of viruses in environmental samples. Appl. Environ. Microbiol. 76, 7251-7258. doi: 10.1128/AEM.01109-10

Sohn, M. B., An, L., Pookhao, N., and Li, Q. (2014). Accurate genome relative abundance estimation for closely related species in a metagenomic sample. BMC Bioinformatics 15:242. doi: 10.1186/1471-2105-15-242

Staals, R. H. J., Jackson, S. A., Biswas, A., Brouns, S. J. J., Brown, C. M., and Fineran, P. C. (2016). Interference-driven spacer acquisition is dominant over naive and primed adaptation in a native CRISPR-Cas system. Nat. Commun. 7:12853. doi: $10.1038 /$ ncomms 12853

Stern, A., Mick, E., Tirosh, I., Sagy, O., and Sorek, R. (2012). CRISPR targeting reveals a reservoir of common phages associated with the human gut microbiome. Genome Res. 22, 1985-1994. doi: 10.1101/gr.138297.112

Steunou, A.-S., Bhaya, D., Bateson, M. M., Melendrez, M. C., Ward, D. M., Brecht, E., et al. (2006). In situ analysis of nitrogen fixation and metabolic switching in unicellular thermophilic cyanobacteria inhabiting hot spring microbial mats. Proc. Natl. Acad. Sci. U.S.A. 103, 2398-2403. doi: 10.1073/pnas. 0507513103

Steunou, A.-S., Jensen, S. I., Brecht, E., Becraft, E. D., Bateson, M. M., Kilian, O., et al. (2008). Regulation of nif gene expression and the energetics of $\mathrm{N}_{2}$ fixation over the diel cycle in a hot spring microbial mat. ISME J. 2, 364-378. doi: 10.1038/ismej.2007.117

Stewart, W. (1970). Nitrogen fixation by blue-green algae in Yellowstone thermal areas. Phycologia 9, 261-268. doi: 10.2216/i0031-8884-9$3-261.1$

Suttle, C. A. (2000) "Cyanophages and their role in the ecology of cyanobacteria," in The Ecology of Cyanobacteria, eds B. A. Whitton and M. Potts (Dordrecht: Springer). doi: 10.1007/0-306-46855-7

Tekere, M., Lötter, A., Olivier, J., Jonker, N., and Venter, S. (2011). Metagenomic analysis of bacterial diversity of Siloam hot water spring, Limpopo, South Africa. Afr. J. Biotechnol. 10, 18005-18012.

Thingstad, T. F., Vage, S., Storesund, J. E., Sandaa, R.-A., and Giske, J. (2014). A theoretical analysis of how strain-specific viruses can control microbial species diversity. Proc. Natl. Acad. Sci. U.S.A. 111, 7813-7818. doi: 10.1073/ pnas. 1400909111

Trifinopoulos, J., Nguyen, L.-T., von Haeseler, A., and Minh, B. Q. (2016). W-IQTREE: a fast online phylogenetic tool for maximum likelihood analysis. Nucleic Acids Res. 44, 1-4. doi: 10.1093/nar/gkw256

Uldahl, K., and Peng, X. (2013). "Biology, biodiversity and application of thermophilic viruses," in Thermophilic Microbes in Environmental and Industrial Biotechnology, eds T. Satyanarayana and K. Y. Littlechild Jennifer (Berlin: Springer), 271-306. doi: 10.1007/978-94-007-5899-5_10

Van der Meer, M. T., Klatt, C. G., Wood, J., Bryant, D. A., Bateson, M. A., Lammerts, L., et al. (2010). Cultivation and genomic, nutritional, and lipid biomarker characterization of roseiflexus strains closely related to predominant in situ populations inhabiting yellowstone hot 
spring microbial mats. J. Bacteriol. 12, 3033-3042. doi: 10.1128/JB. 01610-09

Voorhies, A. A., Eisenlord, S. D., Marcus, D. N., Duhaime, M. B., Biddanda, B. A., Cavalcoli, J. D., et al. (2016). Ecological and genetic interactions between cyanobacteria and viruses in a low-oxygen mat community inferred through metagenomics and metatranscriptomics. Environ. Microbiol. 18, 358-371. doi: 10.1111/1462-2920.12756

Weinbauer, M. G., and Rassoulzadegan, F. (2004). Are viruses driving microbial diversification and diversity? Environ. Microbiol. 6, 1-11. doi: 10.1046/j.14622920.2003.00539.x

Westra, E. R., Dowling, A. J., Broniewski, J. M., and van Houte, S. (2016). Evolution and Ecology of CRISPR. Ann. Rev. Ecol. Evol. Syst. 47, 307-331. doi: 10.1146/ annurev-ecolsys-121415-032428

Wilm, A., Aw, P. P. K., Bertrand, D., Yeo, G. H. T., Ong, S. H., Wong, C. H., et al. (2012). LoFreq: a sequence-quality aware, ultra-sensitive variant caller for uncovering cell-population heterogeneity from high-throughput sequencing datasets. Nucleic Acids Res. 40, 11189-11201. doi: 10.1093/nar/gks918

Wu, Y. W., Simmons, B. A., and Singer, S. W. (2016). MaxBin 2.0: an automated binning algorithm to recover genomes from multiple metagenomic datasets. Bioinformatics 32, 605-607. doi: 10.1093/bioinformatics/btv638

Ye, Y., and Zhang, Q. (2016). Characterization of CRISPR RNA transcription by exploiting stranded metatranscriptomic data. RNA 22, 945-956. doi: 10.1261/ rna.055988.116

Yu, M. X., Slater, M. R., and Ackermann, H.-W. (2006). Isolation and characterization of Thermus bacteriophages. Arch. Virol. 151, 663-679. doi: 10.1007/s00705-005-0667-x
Zablocki, O., van Zyl, L. J., Kirby, B., and Trindade, M. (2017). Diversity of dsDNA viruses in a South African hot spring assessed by metagenomics and microscopy. Viruses 9:348. doi: 10.3390/v91 10348

Zeigler-Allen, L., McCrow, J. P., Ininbergs, K., Dupont, C. L., Badger, J. H., Hoffman, J. M., et al. (2017). The baltic sea virome: diversity and transcriptional activity of DNA and RNA viruses. mSystems 2, e125-16. doi: 10.1128/mSystems. 00125- 16

Zhang, W., Zhou, J., and Wang, Y. (2015). Four novel algal virus genomes discovered from Yellowstone Lake metagenomes. Sci. Rep. 5:15131. doi: 10. 1038/srep15131

Zhou, Y., Lin, J., Li, N., Hu, Z., and Deng, F. (2013). Characterization and genomic analysis of a plaque purified strain of cyanophage PP. Virol. Sin. 28, 272-279. doi: $10.1007 /$ s12250-013-3363-0

Conflict of Interest Statement: The authors declare that the research was conducted in the absence of any commercial or financial relationships that could be construed as a potential conflict of interest.

Copyright (c) 2018 Guajardo-Leiva, Pedrós-Alió, Salgado, Pinto and Díez. This is an open-access article distributed under the terms of the Creative Commons Attribution License (CC BY). The use, distribution or reproduction in other forums is permitted, provided the original author(s) and the copyright owner(s) are credited and that the original publication in this journal is cited, in accordance with accepted academic practice. No use, distribution or reproduction is permitted which does not comply with these terms. 